\title{
Multiphysics Thermal-Fluid Design Analysis of a Non- Nuclear Tester for Hot-Hydrogen Materials and Component Development
}

\author{
Ten-See Wang ${ }^{1}$, John Foote, and Ron Litchford \\ NASA Marshall Space Flight Center, Huntsville, Alabama, 35812 \\ '256-544-0503, ER43, Ten-See.Wang-1@nasa.gov
}

\begin{abstract}
The objective of this effort is to perform design analyses for a non-nuclear hot-hydrogen materials tester, as a first step towards developing efficient and accurate multiphysics, thermo-fluid computational methodology to predict environments for hypothetical solid-core, nuclear thermal engine thrust chamber design and analysis. The computational methodology is based on a multidimensional, finite-volume, turbulent, chemically reacting, thermally radiating, unstructuredgrid, and pressure-based formulation. The multiphysics invoked in this study include hydrogen dissociation kinetics and thermodynamics, turbulent flow, convective, and thermal radiative heat transfers. The goals of the design analyses are to maintain maximum hot-hydrogen jet impingement energy and to minimize chamber wall heating. The results of analyses on three test fixture configurations and the rationale for final selection are presented. The interrogation of physics revealed that reactions of hydrogen dissociation and recombination are highly correlated with local temperature and are necessary for accurate prediction of the hot-hydrogen jet temperature.
\end{abstract}

Keywords: Multiphysics, computational fluid dynamics, nuclear thermal engine.

PACS: 47.11.+j; Computational methods in fluid dynamics.

\section{INTRODUCTION}

Nuclear thermal propulsion (NTP) may open up the solar system to far broader and faster exploration than is now possible with chemical propulsion. The feasibility of NTP systems was established by extensive testing in the Rover/NERVA programs and the technical merits of NTP have been identified in numerous studies (Koenig, 1986). In a NTP system, the propellant is heated by a nuclear reactor instead of combustion. The best NTP propellant is hydrogen with which high exhaust speed can be achieved with its low molecular weight, resulting in high thrust per unit mass of propellant consumed. Under the operating temperature inside a nuclear reactor, often at $2,500 \sim 3,000 \mathrm{~K}$, the heated hydrogen further dissociates into atomic hydrogen - at a formula weight only half that of molecular hydrogen, indicating an even greater thrust may be realized. The heat transfer efficiency and degree of hydrogen dissociation are therefore two important performance factors for NTP. On the other hand, the need to push fuel element temperature to extremes in order to maximize performance also intensifies hydrogen induced corrosion rates, which are known to increase in direct proportion to reactor operating temperature (Lyon, 1973). In order to develop candidate high temperature fuel materials that would be compatible with the hot-hydrogen environment of a high performance solid core NTP engine, a nonnuclear test effort entitled "Hot Hydrogen Materials and Component Development" is underway at NASA's Marshall Space Flight Center (MSFC), while a parallel task entitled "Multiphysics Thrust Chamber Modeling" is also in progress in order to develop a computational methodology capable of predicting the thermal-fluid environment in a nuclear thermal engine thrust chamber. This computational methodology is based on an Unstructured-grid Navier-Stokes Internai-externai computational fluid dynamics (CFD) Cơde (UNIC). Physical and numcrical modcls pertinent to solidcore NTP will be developed and implemented. The hot gas and material temperatures to be measured in the hothydrogen materials development tests will be used to benchmark the UNIC code. In this effort, the design part of the UNIC capability was demonstrated by performing design analyses for three hot hydrogen materials tester configurations and a final configuration was recommended. The effect of configuration changes on design goals was presented and the effects of hydrogen dissociation and thermal radiation on the computed thermophysics were investigated. 


\section{TEST FIXTURE BASELINE DESIGN}

The baseline design of the apparatus for testing tubular fuel materials is shown in Fig. 1. It is directly mated to an arc-heater (not shown) that provides hot-hydrogen flow. Optical ports are fitted to allow real-time pyrometer and laser diagnostics measurements for material surface temperature and centerline gas temperature, respectively. As the hot-hydrogen jet travels the length of the chamber, it loses energy to the water-cooled copper chamber and sample material. As the sample material heats up, it loses energy to the colder chamber wall by thermal radiation. The first design goal is therefore minimizing the energy loses of the hydrogen jet. As the temperature of the hydrogen jet reaches that of NTP operating condition, the heat load imposed on the copper chamber may exceed its design limit, due to both the convective heating from hydrogen jet and bombardment of thermal radiation from hot sample. The second design goal is therefore to minimize the heat load on the copper chamber wall.

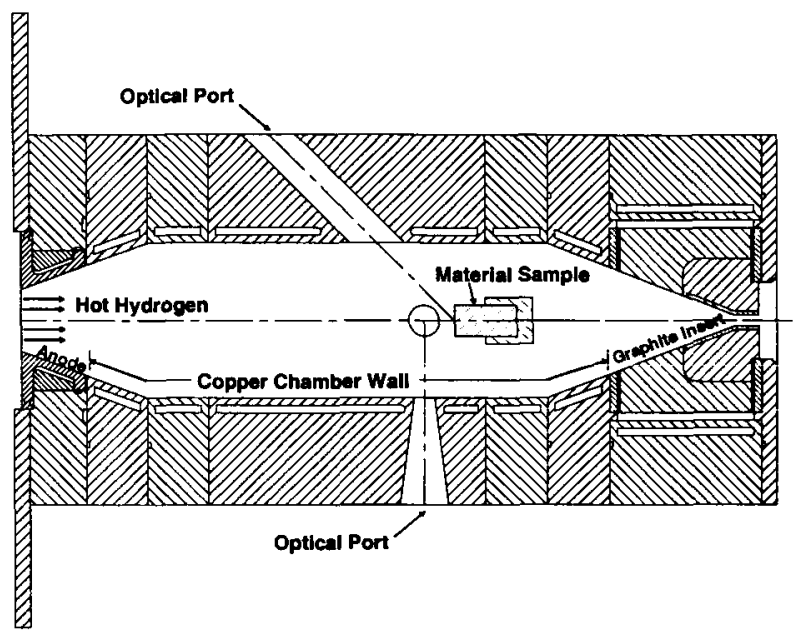

FIGURE 1. Baseline Design of the Test Fixture.

\section{COMPUTATIONAL METHODOLOGY}

The design analyses were performed using UNIC CFD methodology. UNIC is a multidimensional, finite-volume, turbulent, chemically reacting, thermally radiating, unstructured-grid, and pressure-based formulation. The all-speed flow nature makes it suitable for describing the thermophysics encountered in a NTP environment. UNIC was developed recently through several activities, namely the launch vehicle base-heating (Chen, 2001), Laser propulsion (Wang, 2002), and stageseparation (Chen, 2002). Most recently, UNIC was benchmarked for steady-state heat transfer and thrust performance for the Space Shuttle Main Engine (SSME) (Wang, 2004) and SSME transient thrust chamber side load (Wang, 2005). To describe the thermal-fluid design environment of the tester, UNIC solves the time-varying transport equations of continuity, species continuity, momentum, total enthalpy, turbulent kinetic energy, and turbulent kinetic energy dissipation:

$$
\begin{gathered}
\frac{\partial \rho}{\partial t}+\frac{\partial}{\partial x_{j}}\left(\rho u_{j}\right)=0 \\
\frac{\partial \rho \alpha_{i}}{\partial t}+\frac{\partial}{\partial x_{j}}\left(\rho u_{j} \alpha_{j}\right)=\frac{\partial}{\partial x_{j}}\left[\left(\rho D+\frac{\mu_{t}}{\sigma_{\alpha}}\right) \frac{\partial \alpha_{i}}{\partial x_{j}}\right]+\omega_{i} \\
\frac{\partial \rho u_{i}}{\partial t}+\frac{\partial}{\partial x_{j}}\left(\rho u_{j} u_{i}\right)=-\frac{\partial p}{\partial x_{i}}+\frac{\partial \tau_{i j}}{\partial x_{j}} \\
\frac{\partial \rho H}{\partial t}+\frac{\partial}{\partial x_{j}}\left(\rho u_{j} H\right)=\frac{\partial p}{\partial t}+Q_{r}+\frac{\partial}{\partial x_{j}}\left(\left(\frac{K}{C_{p}}+\frac{\mu_{t}}{\sigma_{H}}\right) \nabla H\right)+\frac{\partial}{\partial x_{j}}\left(\left(\left(\mu+\mu_{t}\right)-\left(\frac{K}{C_{p}}+\frac{\mu_{t}}{\sigma_{H}}\right)\right) \nabla\left(V^{2} / 2\right)\right)+\theta \\
\frac{\partial \rho k}{\partial t}+\frac{\partial}{\partial x_{j}}\left(\rho u_{j} k\right)=\frac{\partial}{\partial x_{j}}\left[\left(\mu+\frac{\mu_{t}}{\sigma_{k}}\right) \frac{\partial k}{\partial x_{j}}\right]+\rho(\Pi-\varepsilon) \\
\frac{\partial \rho \varepsilon}{\partial t}+\frac{\partial}{\partial x_{j}}\left(\rho u_{j} \varepsilon\right)=\frac{\partial}{\partial x_{j}}\left[\left(\mu+\frac{\mu_{t}}{\sigma_{\varepsilon}}\right) \frac{\partial \varepsilon}{\partial x_{j}}\right]+\rho \frac{\varepsilon}{k}\left(C_{1} \Pi-C_{2} \varepsilon+C_{3} \Pi^{2} / \varepsilon\right)
\end{gathered}
$$


A predictor and corrector solution algorithm was employed to provide coupling of the fluid governing equations. A second-order central-difference scheme was employed to discretize the diffusion fluxes and source terms of the governing equations. For the convective terms, a second-order upwind total variation diminishing difference scheme was used in this effort. A point-implicit (operator splitting) method was employed to solve the finite-rate chemistry system. An extended k- $\varepsilon$ turbulence model (Chen, 1987) was used to describe the turbulence.

The convective heat transfer follows the modified Newtonian law

$$
Q_{c}=\left(\rho u_{\tau} / T^{+}\right)\left(h_{w}-h_{p}-R\left(u_{p}^{2} / 2\right)\right)
$$

The radiative heat transfer is analyzed by solving the radiative transfer equation

$$
(\Omega \cdot \nabla) I(r, \Omega)=-\kappa I(r, \Omega)+\kappa I_{b}(r)
$$

Discrete ordinate method was used to solve the radiative transfer equation. The radiative heat flux is given by the integration of the wall leaving radiative intensities

$$
Q_{r}=\int_{n \Omega^{-}<0} I\left(r, \Omega^{-}\right)\left|n \Omega^{-}\right| d \Omega^{-}
$$

Details of the numerical algorithm can be found in (Wang, 2003 and 2004).

\section{Boundary Conditions}

No-slip condition was applied to the solid walls. Fixed mass flow rate boundary condition was used at the inlet, and mass conservation boundary condition was used at the exit. For a conservative calculation of the chamber wall heat flux, a fixed temperature of $400 \mathrm{~K}$ was estimated for the chamber wall and the hot-hydrogen temperature was set at $3500 \mathrm{~K}$. For the shield configuration, the wall temperature of the upper shield facing the chamber wall was estimated to be 2600 $\mathrm{K}$ from a separate one-dimensional heat transfer calculation. Adiabatic condition was applied to walls of sample, funnel (for funnel configuration), lower shield and flanges, and graphite insert. The hydrogen inlet mass flow rate was $10 \mathrm{~g} / \mathrm{s}$ and the chamber pressure was $35 \mathrm{~atm}$. An emissivity of 0.6 was applied to the copper chamber wall, whereas an emissivity of 0.4 was applied to the shield. The emissivity for the rest of the solid walls was set at 0.9 . The inlet boundary was considered as a radiating wall to approximate the radiation from the arc-heater section. A series of pre-calculations were performed on the baseline case to iterate the inlet temperature and species concentrations such that the inlet species concentrations correspond to a state of temperature at $3500 \mathrm{~K}$.

\section{DESIGN ANALYSIS}

Multiphysics invoked in this effort include turbulence, hydrogen reactions (Wang, 2001) and its associated thermodynamics, convective heat transfer, and surface radiation. The goals of this design are to maintain the $3500 \mathrm{~K}$ hot-hydrogen jet as long as possible as it impinges on the sample and to hold the overall chamber wall heat flux below a pre-determined $5.0 \times 10^{6} \mathrm{~W} / \mathrm{m}^{2}$.

\section{Baseline Design}

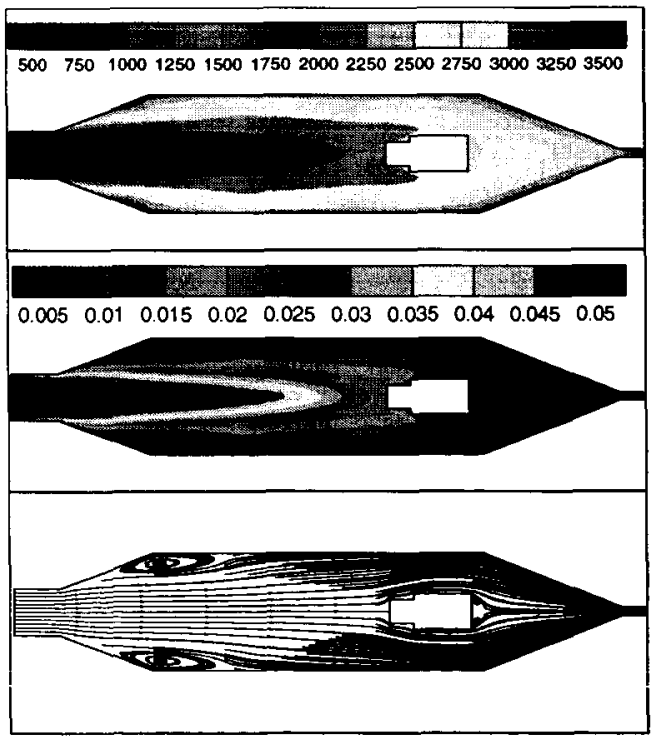

FIGURE 2. Computed Temperature, H Mass Fraction Contours and Streamlines for Baseline Design. 
The hot hydrogen $\left(\mathrm{H}_{2}\right)$ environment of the baseline design was computed and Figure 2 shows the computed temperature, hydrogen atom $(\mathrm{H})$ mass fraction contours and flow streamlines. Temperature contours show the temperature drop of the hot-hydrogen jet, as it loses energy to the colder copper chamber wall due to both convection and sample surface radiation processes. As the hot jet cools, $\mathrm{H}$ recombines to become $\mathrm{H}_{2}$ and it can be seen from the $\mathrm{H}$ contours that higher concentration of $\mathrm{H}$ is correlated with hotter local temperature. The streamline plot shows an expanding hot-hydrogen jet impinging on and flowing around the sample block, and later exhausting into the convergent exit section. The sample block is heated by the hot-hydrogen jet and its integrity under such a high temperature environment is the subject of the test. A large recirculation zone appears in the divergent section of the chamber, while a small recirculation region forms behind the sample holder; both of which are strongly affected by the turbulence. Note although the plots in Fig. 1 showing a distinctive strong hot-hydrogen jet and two recirculated flow regions, the pressure and Mach number contours are fairly uniform inside the chamber (not shown) for this design, due to the largely low subsonic flow field.

Figure 3 shows the computed centerline temperature profiles from inlet to the sample front face for the baseline design. The end of the curves is the stagnation point. The results of four cases are presented in here, with combinations of frozen and finite-rate chemistries and with and without surface radiation. Finite-rate chemistry considers the $\mathrm{H}_{2}$ dissociation and $\mathrm{H}$ recombination, while the frozen chemistry freezes the inlet flow composition. The centerline line temperatures appear to maintain its value until the energy dissipation starts to take over and they drop rapidly until reaching the stagnation point. Without surface radiation, the central surface (stagnation) temperatures for frozen and finite-rate chemistries are 2954.1 and $3170.8 \mathrm{~K}$, respectively. The temperature computed by frozen chemistry is $216.7 \mathrm{~K}$ lower because thermodynamic properties were computed based on an unphysical frozen composition, indicating the importance of finite-rate chemistry in arriving accurate thermal-fluid solution. With surface radiation, the central sample surface temperatures drop further due to surface energy exchange with the colder chamber wall, resulting in stagnation temperatures of 2805.6 and $3052.8 \mathrm{~K}$ for frozen and finite-rate chemistries, respectively. Figure 3 demonstrates the importance of the inclusion of both hydrogen dissociation and surface radiation in the design analysis. Figure 3 also

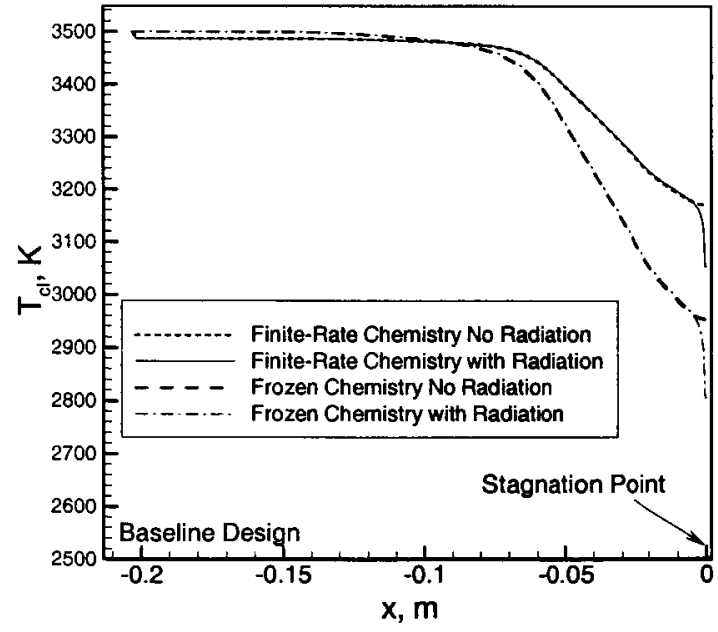

FIGURE 3. Computed Centerline Temperature Profiles from Inlet to Stagnation Point for Baseline Design Cases.

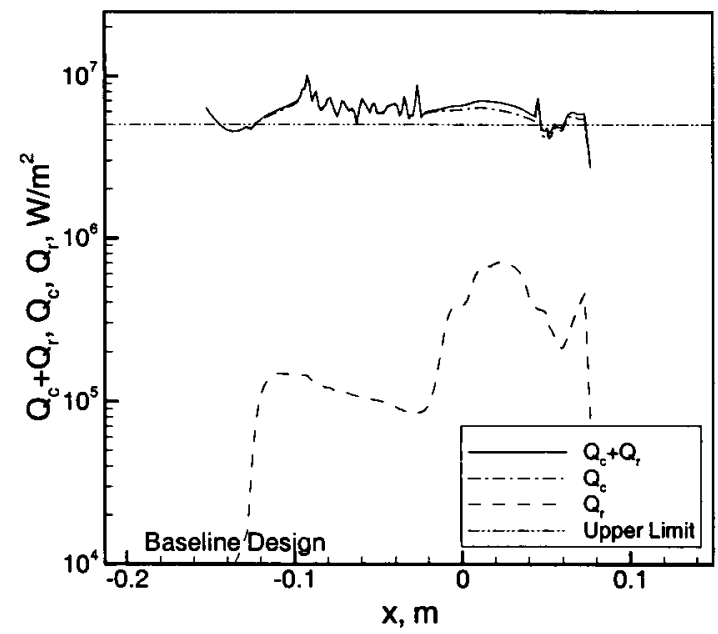

FIGURE 4. Computed Total, Convective, and Radiative Heat Fluxes on Chamber Wall for Baseline Design.

shows that the approximately $450 \mathrm{~K}$ temperature drop from the inlet to the stagnation point indicating too much energy dissipation and the baseline design needs to be improved. In addition, the $118.0 \mathrm{~K}$ temperature drop with and without radiation indicates a radiation shield may be in order.

Figure 4 shows the computed total, convective, and radiative heat fluxes along the chamber wall, between anode and graphite insert sections. Although the surface radiation caused $118.0 \mathrm{~K}$ drop in stagnation temperature, the radiative heat flux is much lower than that of the convective heat flux in comparison. This is because the area of the sample radiating surface is much smaller than that of the fluid-chamber contact surface. And neither $\mathrm{H}_{2}$ nor $\mathrm{H}$ is participating medium for radiation. Figure 4 also reveals that the total heat flux is mostly above $5 \times 10^{6} \mathrm{~W} / \mathrm{m}^{2}$ along the chamber surface, with a peak heat flux at about $1 \times 10^{7} \mathrm{~W} / \mathrm{m}^{2}$ at the hot-hydrogen flow impingement point on the chamber, indicating the baseline 
design may have overheating issue as well.

\section{Funnel Design}

The second design involves placing a funnel in front of the coupon. A funnel would concentrate the hot-hydrogen flow and possibly shield part of the convective energy exchange between the hot jet and the cooled chamber, while also serve as a partial radiation-shield.

Figure 5 shows the computed temperature, $\mathrm{H}$ concentration and streamlines for the funnel design. It can be seen that the expansion of the hot-hydrogen jet in the divergent section is forced to converge into a more energy concentrated jet, by the funnel. This is evident by the slower decreasing slope of the centerline temperature profiles in Fig. 6, comparing to the steep decreasing slope of those in Fig. 3. The stagnation temperatures are $3172.0 \mathrm{~K}$ (with radiation) and $3191.7 \mathrm{~K}$ (without radiation). The stagnation temperature drop with and without radiation is now only $19.7 \mathrm{~K}$, indicating that the funnel indeed serves as a partial radiation shield. And again the higher concentration of $\mathrm{H}$ associates with higher temperatures.

The flowfield of the funnel design however, is not as uniform as that of the baseline design. As the higher energy, concentrated hot-hydrogen jet impinges on the sample, instead of flowing around it smoothly as in the baseline case, it forms a stronger jet impinging on the chamber wall, as indicated in the streamline plot in Fig. 5. That results in a peak total chamber wall heat flux of $1.54 \times 10^{7} \mathrm{~W} / \mathrm{m}^{2}$, exceeding the maximum heat flux desirable, as indicated in Fig. 7. In fact, the overall total heat flux exceeds the desired $5 \times 10^{6} \mathrm{~W} / \mathrm{m}^{2}$, except at the root of the funnel.

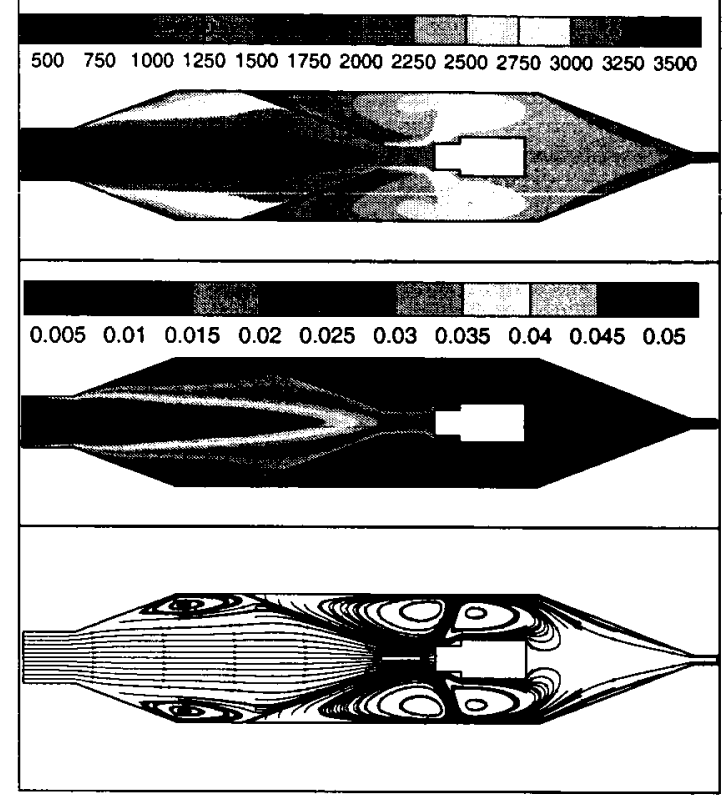

FIGURE 5. Computed Temperature, H Mass Fraction Contours and Streamlines for Funnel Design.

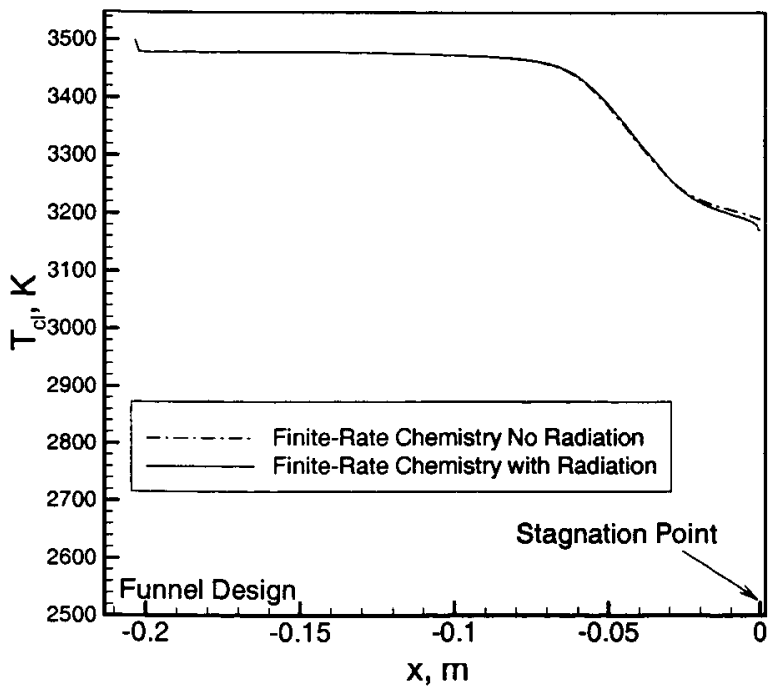

FIGURE 6. Computed Centerline Temperature Profiles from Inlet to Sample Front Face for Funnel Design Cases.

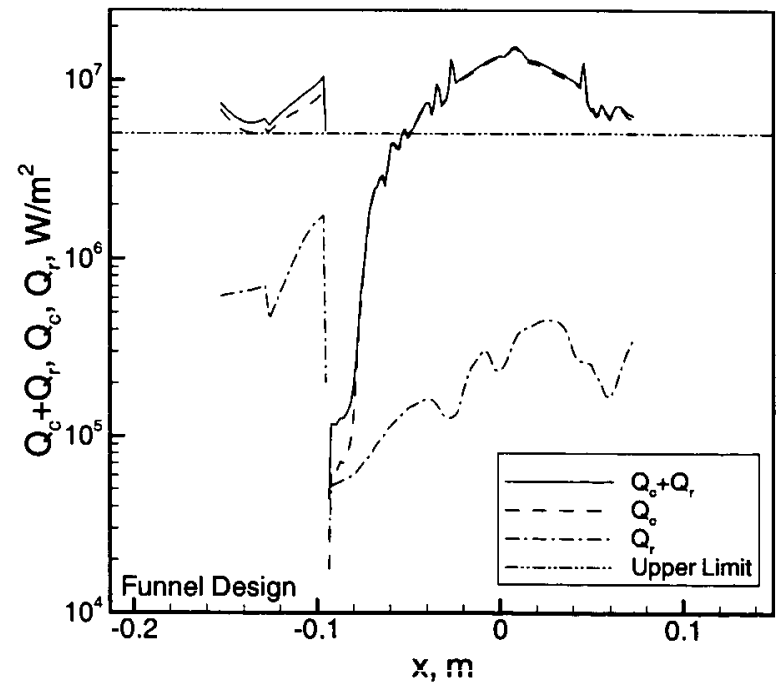

FIGURE 7. Computed Total, Convective, and Radiative Heat Fluxes on Chamber Wall for Funnel Design. 


\section{Shield Design}

The third design involves a Tungsten shield that almost completely shields the chamber wall from the convective heating and is supported by a $360^{\circ}$ Flange. The beginning of the shield is closed off at the intersection of the chamber and the anode cap so that no hot flow can get in between the shield and chamber wall. Without the $360^{\circ}$ Flange and the closeoff, a separate calculation indicated that a flow pumping effect is invoked and the hot hydrogen is sucked into the region between the chamber the shield.

Figure 8 shows the computed temperature, $\mathrm{H}$ concentration contours and streamlines for the shield design. It can be seen from the temperature contours that the flow is now uniformly hotter than that of the baseline design, because the convective heat loss is mostly shielded. The $\mathrm{H}$ jet is now propagating the longest while wrapping around the coupon, indicating minimum energy dissipation for the hot jet. The $\mathrm{H}$ concentration between the chamber and the shield is low because of the low local temperature. The flow streamlines look very similar to those of the baseline design except the flow speed is a little faster due to the smaller effective flowing area, resulting in a smaller recirculation bubble at the divergent section.

Figure 9 shows that the dropping rate of the centerline temperatures is now very slow, comparing to those of Fig. 3 and 6 . The stagnation temperatures are $3426.0 \mathrm{~K}$ with radiation, and $3440.7 \mathrm{~K}$ without radiation. The computed stagnation temperatures with and without thermal radiation

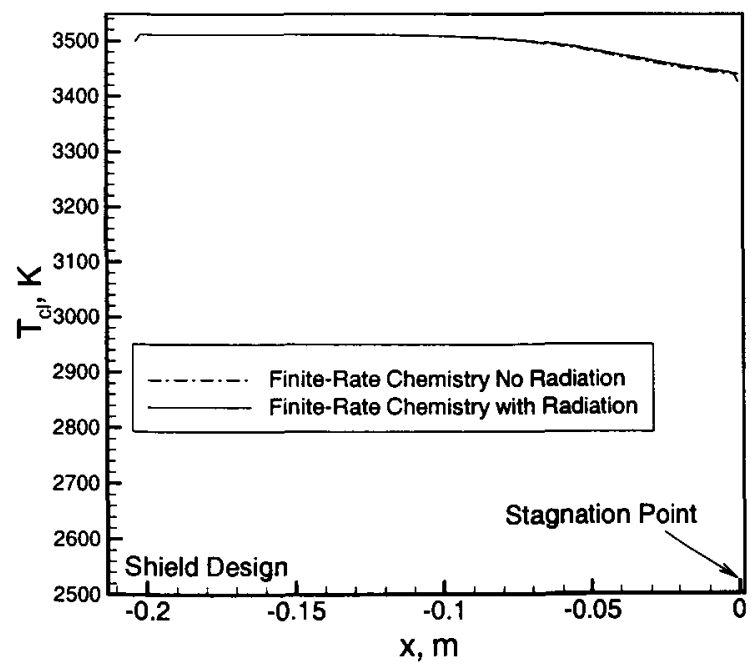

FIGURE 9 Computed Centerline Temperature Profiles for Shield Configuration Cases.

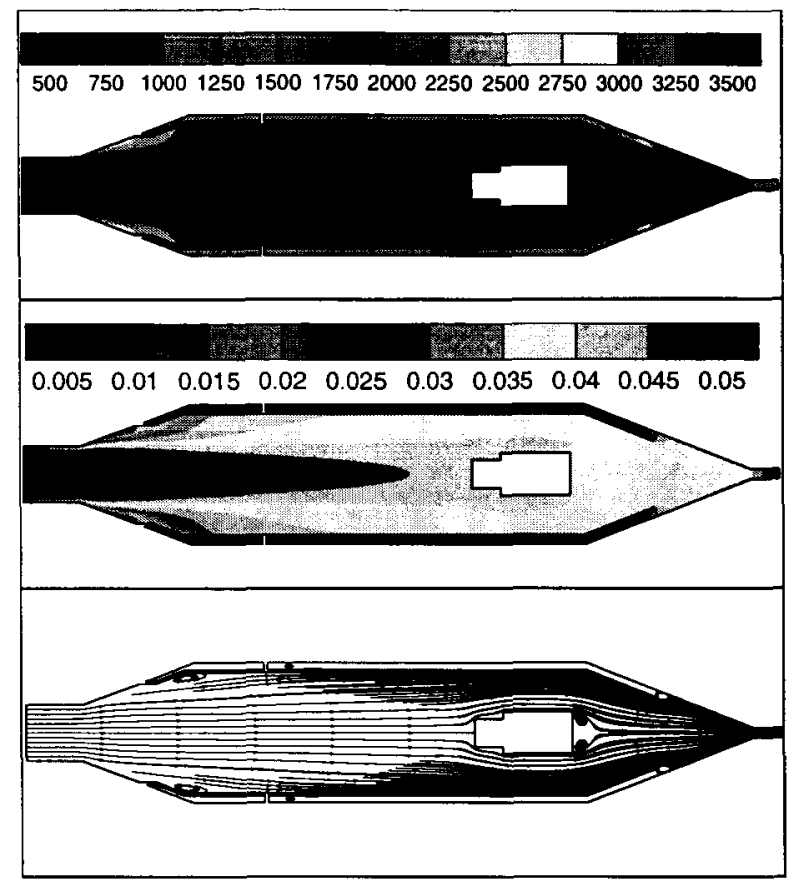

FIGURE 8. Computed Temperature, H Mass Fraction Contours and Streamlines for Shield Design.

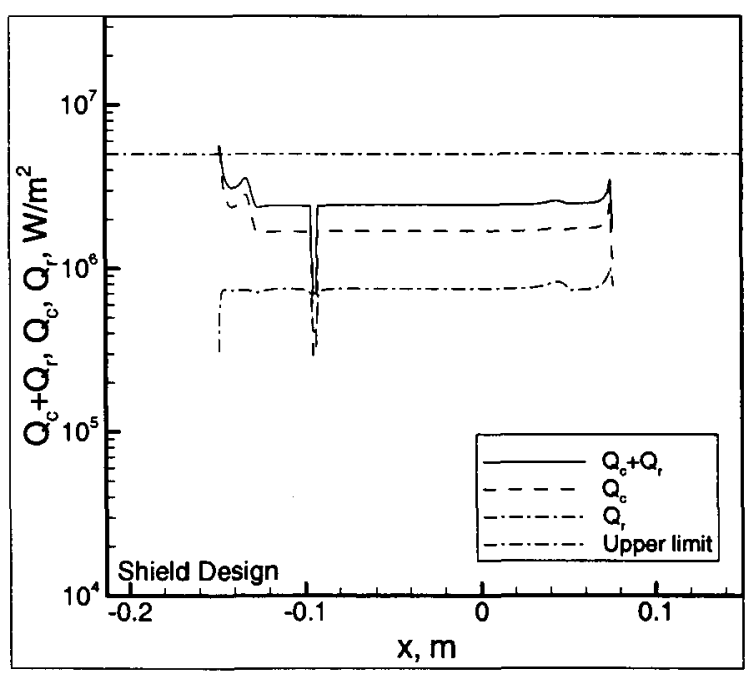

FIGURE 10. Computed Total, Convective, and Radiative Heât Fluxes ôn Chamber Wall for Shield Desigñ.

calculation for all three designs are summarized in Table 1. The smallest stagnation temperature drop of $14.7 \mathrm{~K}$ with and without radiation indicating this shield is also a very effective radiation shield. Figure 10 shows the average total heat flux is now an acceptable $2.5 \times 10^{6} \mathrm{~W} / \mathrm{m}^{2}$, lower than the $5 \times 10^{6} \mathrm{~W} / \mathrm{m}^{2}$ limit. There is a peak total heat flux of $5.65 \times 10^{6}$ 
$\mathrm{W} / \mathrm{m}^{2}$ right behind the close-off shield that is probably caused by the pre-determined $2600 \mathrm{~K}$ for the chamber-facing shield surface. Since the close-off part of the shield is connected to the cold chamber wall at $400 \mathrm{~K}$, it is believed that the shield surface temperature at the close-off should be lower due to conduction, resulting in lower local gas temperature, and therefore lower peak heat flux if a coupled conjugate heat transfer calculation was conducted. The streamlines plot show a small recirculation bubble at the end of the shield, resulting in a second peak flux of $3.46 \times 10^{6} \mathrm{~W} / \mathrm{m}^{2}$, also lower than the threshold. The shield configuration is therefore the design satisfying both design criteria. Figure 11 shows the test fixture for testing rod-shaped fuel materials with this shield design.

Table 1. Computed Stagnation Temperatures for Three Test Fixture Designs.

\begin{tabular}{cccc}
\hline Design & $\begin{array}{c}\text { Without } \\
\text { Radiation, } \mathrm{K}\end{array}$ & $\begin{array}{c}\text { With } \\
\text { Radiation, } \mathrm{K}\end{array}$ & $\Delta, \mathbf{K}$ \\
\hline baseline & 3170.8 & 3052.8 & 118.0 \\
funnel & 3191.7 & 3172.0 & 19.7 \\
shield & 3440.7 & 3426.0 & 14.7 \\
\hline
\end{tabular}

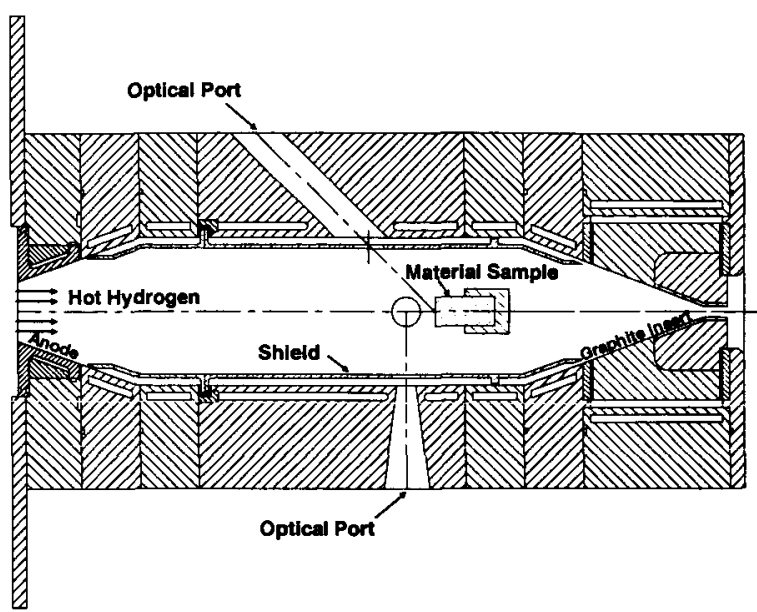

FIGURE 11. Shield Design.

\section{CONCLUSION}

Multiphysics computational analyses were performed to support the design of test fixtures for non-nuclear testing of fuel materials. Multiphysics invoked include hydrogen dissociation kinetics and thermodynamics, turbulent flow, convective, and thermal radiative heat transfers. The design criteria were to maximize the hot-hydrogen temperature while impinging on the test coupon, and to minimize the total heat flux imposed on the copper chamber wall. Results of the design analyses indicate that the shield design provides the lowest chamber wall total heat flux and the highest hot hydrogen delivering temperature, thereby is superior to the baseline and funnel designs. The effects of sample surface radiation on chamber heat flux and sample stagnation temperature were presented. It was also found that hydrogen dissociation and recombination reactions are highly correlated with local temperature and are very important in accurate prediction of the chamber thermo-flowfield.

\section{NOMENCLATURE}

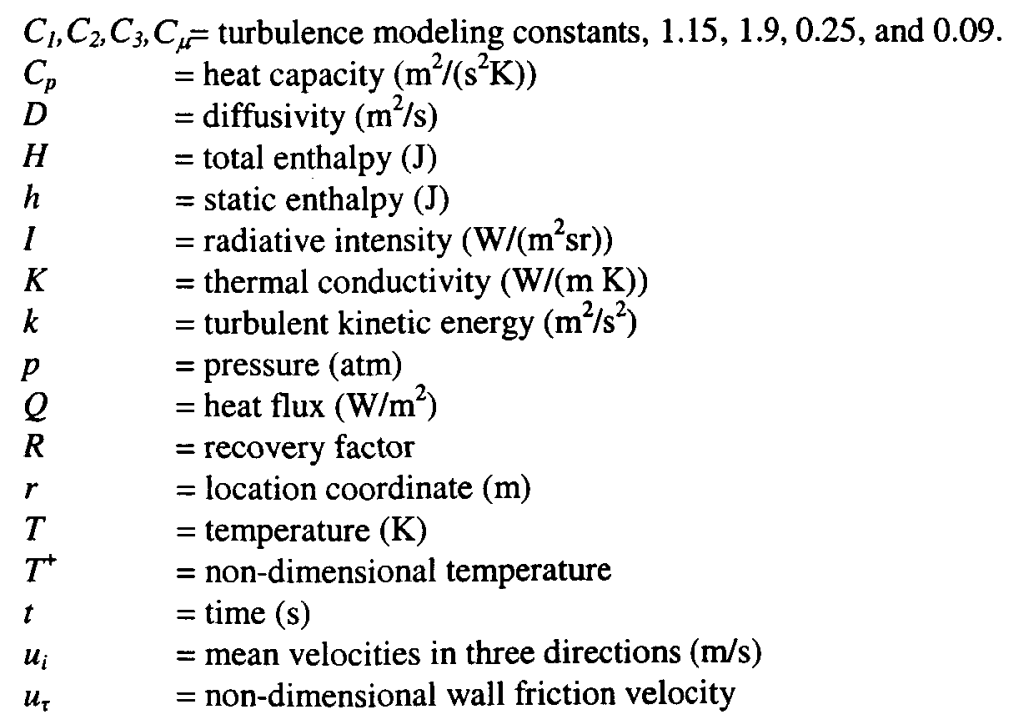




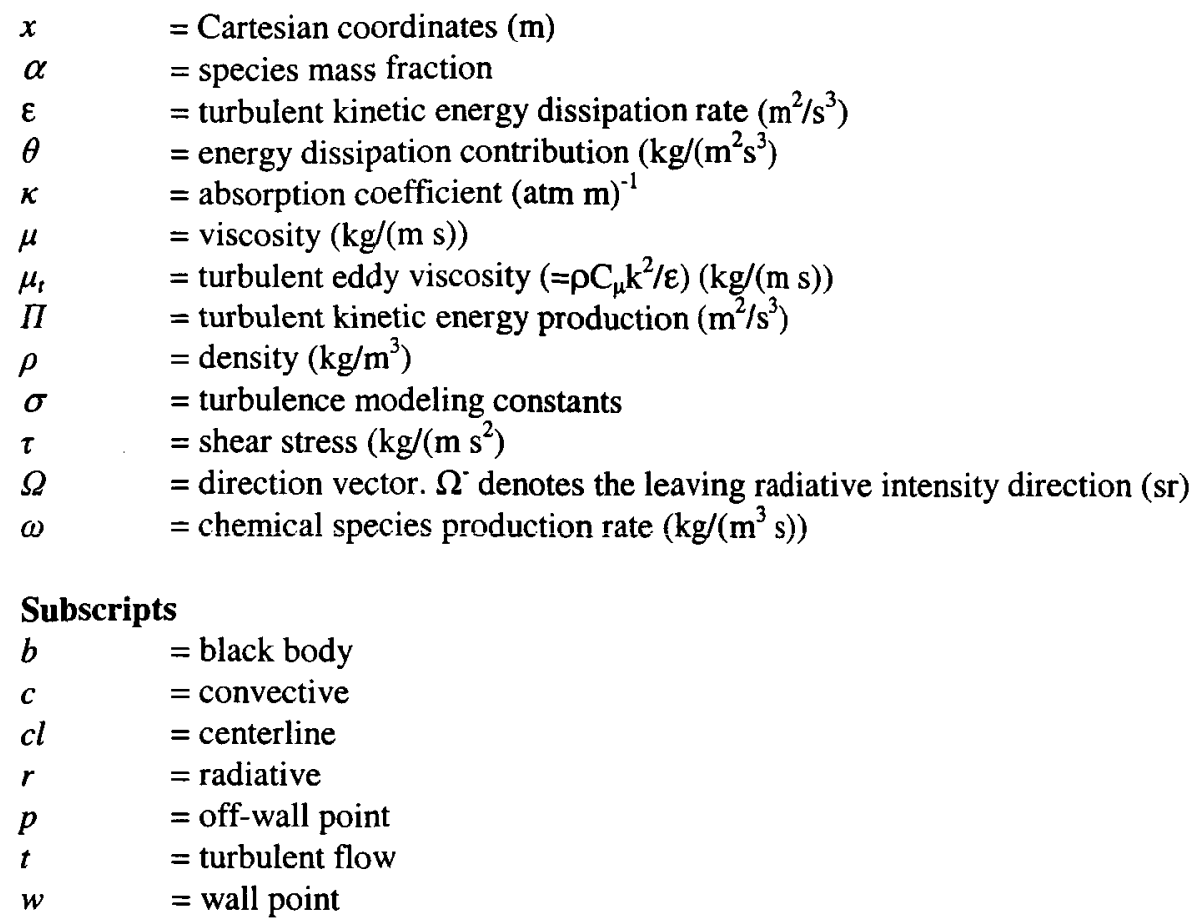

\section{ACKNOWLEDGMENTS}

This study was partially supported by a Nuclear Systems Office task entitled "Multiphysics Thrust Chamber Modeling" and by a MSFC Internal Research and Development focus area task entitled "Hot-Hydrogen Materials and Component Development."

\section{RFERENCES}

Koenig, D.R., "Experience Gained from the Space Nuclear Rocket Program (Rover)," LA-10062-H, Los Alamos National Laboratory, Los Alamos, New Mexico, May 1986.

Lyon, L.L., "Performance of (U,Zr)C-Graphite (Composite) and of (U,Zr)C (Carbide) Fuel Elements in the Nuclear Furnace 1 Test Reactor," LA-5398-MS, Los Alamos Scientific Laboratory, Los Alamos, New Mexico, Sept. 1973.

Chen, Y.-S., Liu, J., Zhang, S., and Mallapragada, P., "An Integrated Tool for Launch Vehicle Base-Heating Analysis," Final Report, Engineering Sciences, Inc., Huntsville, AL, December, 2001.

Wang, T.-S., Chen, Y.-S., Liu, J., Myrabo, L.N., and Mead, F.B. Jr., "Advanced Performance Modeling of Experimental Laser Lightcraft," Journal of Propulsion and Power, 18, 1129-1138 (2002).

Chen. Y.-S., Zhang S., and Liu, J., "Stage Separation Performance Analysis Project," Final Report, Engineering Sciences, Inc., Huntsville, AL, June, 2002.

Wang, T.-S., "Multidimensional Unstructured-Grid Liquid Rocket Engine Nozzle Performance and Heat Transfer Analysis," AIAA Paper 2004-4016, 40 ${ }^{\text {th }}$ AIAA/ASME/SAE/ASEE Joint Propulsion Conference, Fort Lauderdale, Florida, 2004.

Wang, T.-S., "Transient 3-D Analysis of Nozzle Side Load in Regeneratively Cooled Engines," AIAA Paper 20053942, $41^{\text {st }}$ AIAA/ASME/SAE/ASEE Joint Propulsion Conference, Tucson, Arizona, 2005.

Chen, Y.-S., and Kim, S. W., "Computation of Turbulent Flows Using an Extended k- $\varepsilon$ Turbulence Closure Model," NASA CR-179204, Oct. 1987.

Wang, T.-S., "Thermophysics Characterization of Kerosene Combustion," Journal of Thermophysics and Heat Transfer, 15, 140-147 (2001). 


\title{
Multiphysics Thermal-Fluid Design Analysis of a Non- Nuclear Tester for Hot-Hydrogen Materials and Component Development
}

\author{
Ten-See Wang ${ }^{1}$, John Foote, and Ron Litchford \\ NASA Marshall Space Flight Center, Huntsville, Alabama, 35812 \\ '256-544-0503, ER43, Ten-See.Wang-l@nasa.gov
}

\begin{abstract}
The objective of this effort is to perform design analyses for a non-nuclcar hot-hydrogen marerials rester, as a first step rowards developing efficient and accurate multiphysics, themo-fluid computational methodology to predict cnvironments for hypothetical solid-core, nuclear thermal engine thrust chamber design and analysis. The computational methodology is based on a multidimensional, finite-volume, turbulent, chemically reacting, chamally radiating, unstructuredgrid, and pressurc-based formulation. The multiphysics invoked in this study include hydrogen dissociation kinetics and thermodynamics, turbulent flow, convective, and thermal radiarive heat transfers. The goals of the design analyses are to maintain maximum hot-hydrogen jet impingement energy and to minimize chamber wall hearing. The results of analyses on thrce test fixnure configurations and the rationale for final selection are presented. The interrogation of physics revealed that reactions of hydrogen dissociation and recombination are highly correlated with local temperature and are necessary for accurare prediction of the hot-hydrogen jet temperature.
\end{abstract}



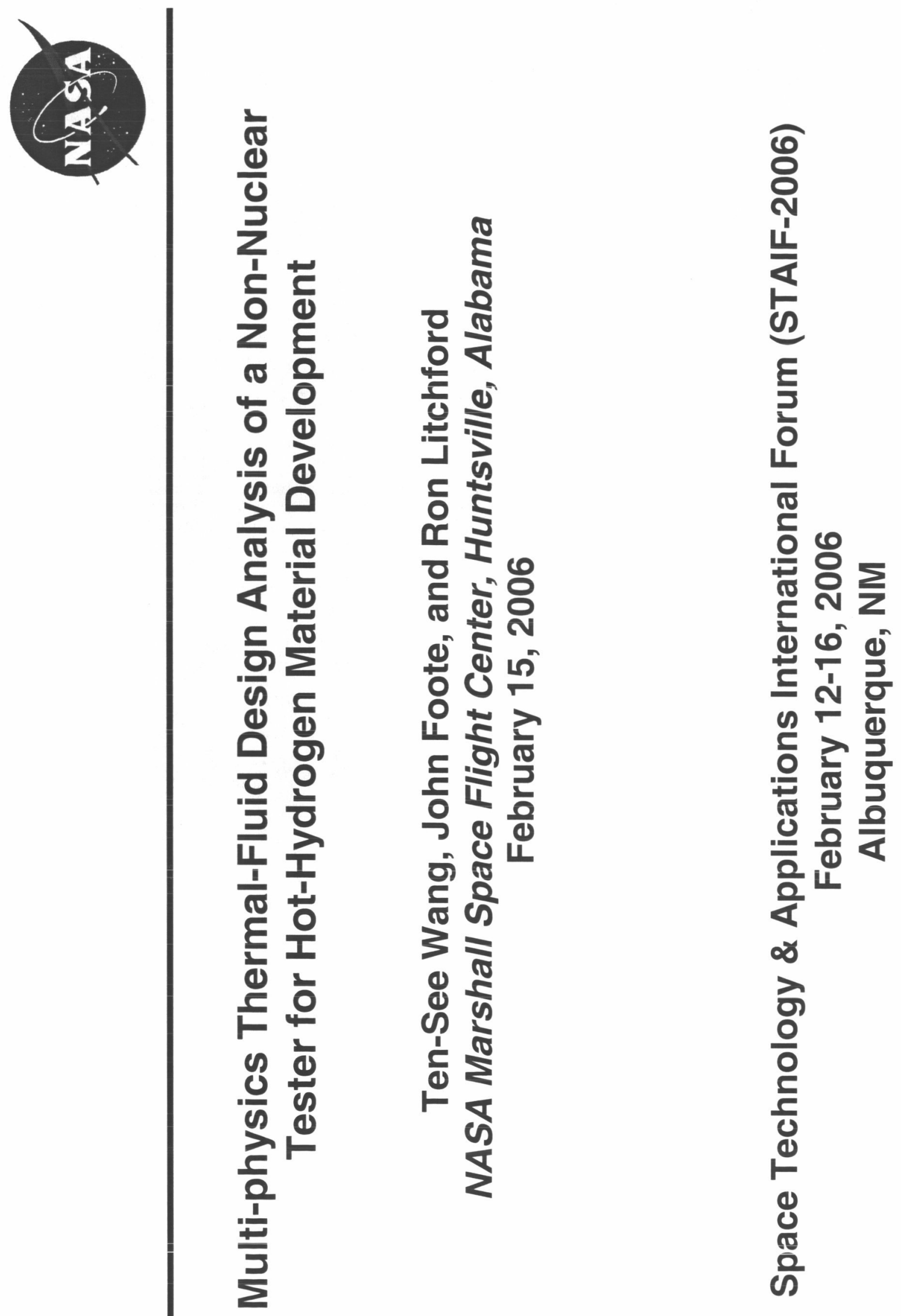

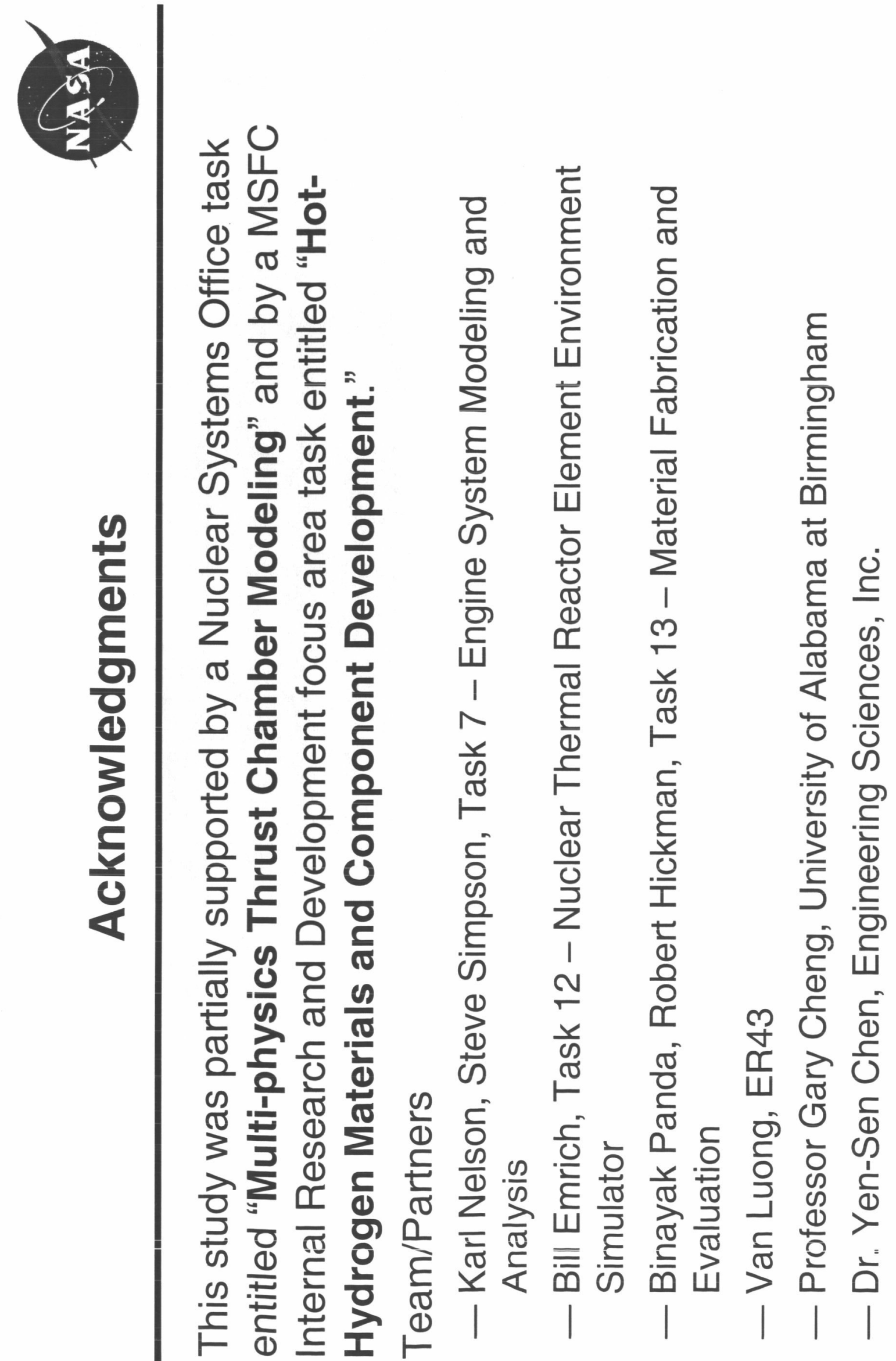


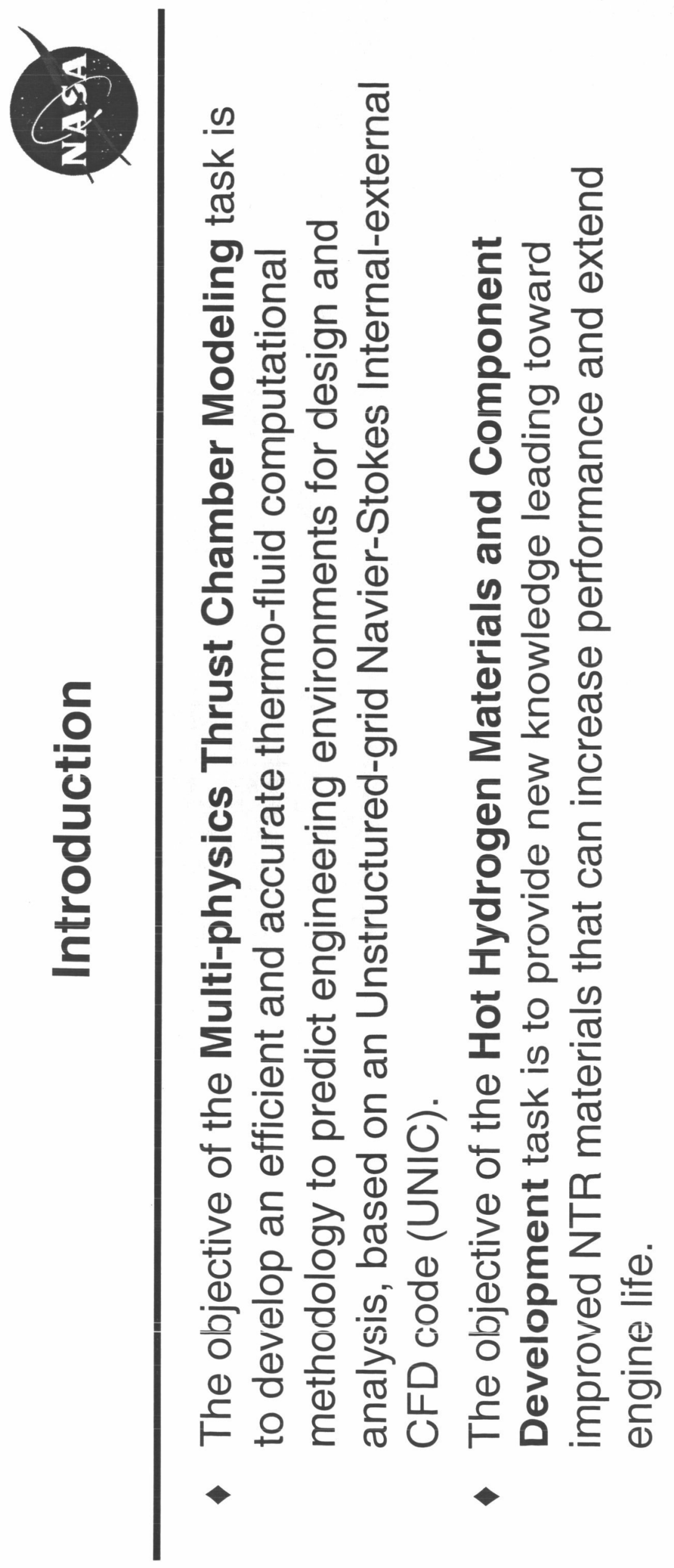




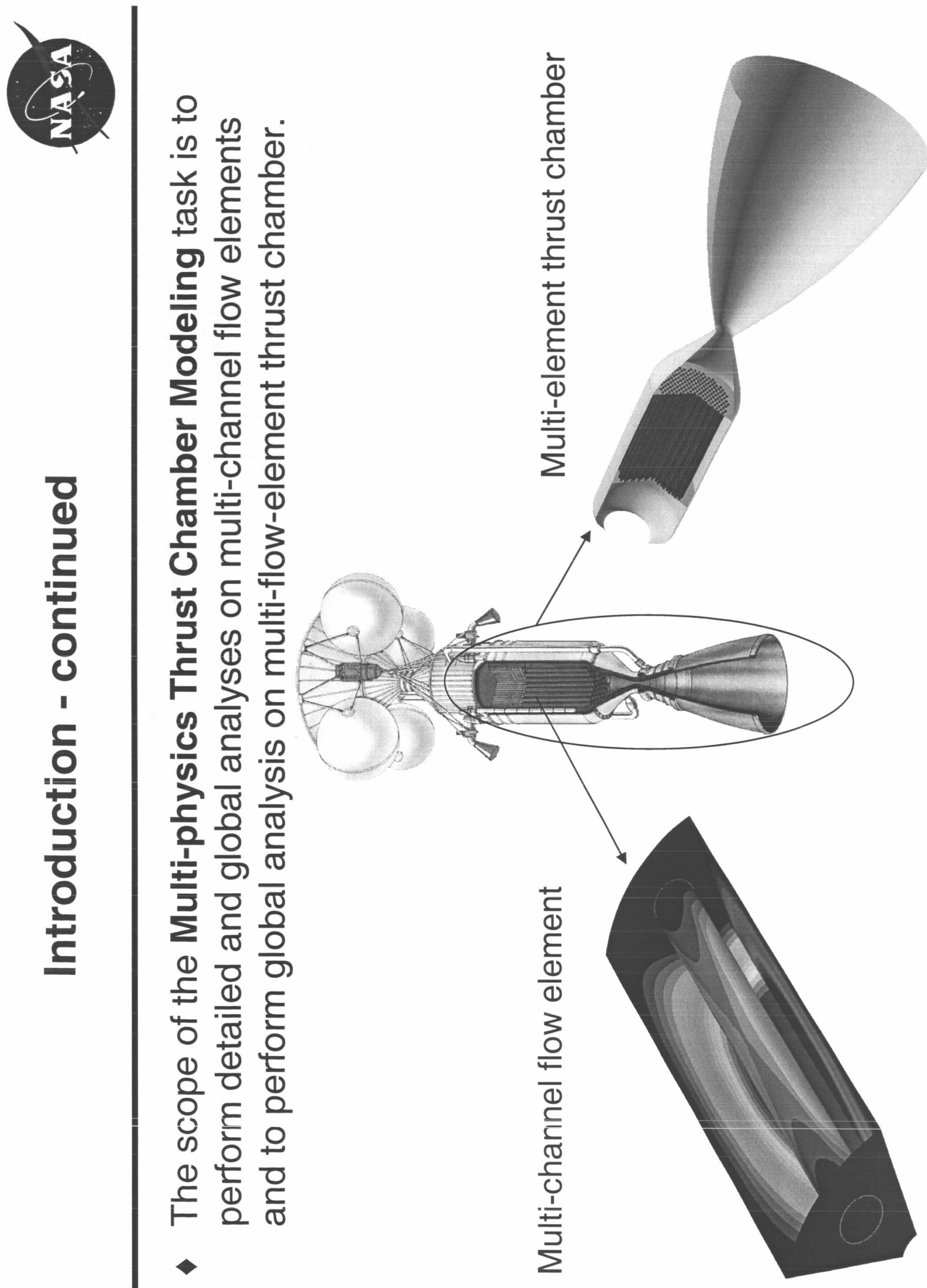




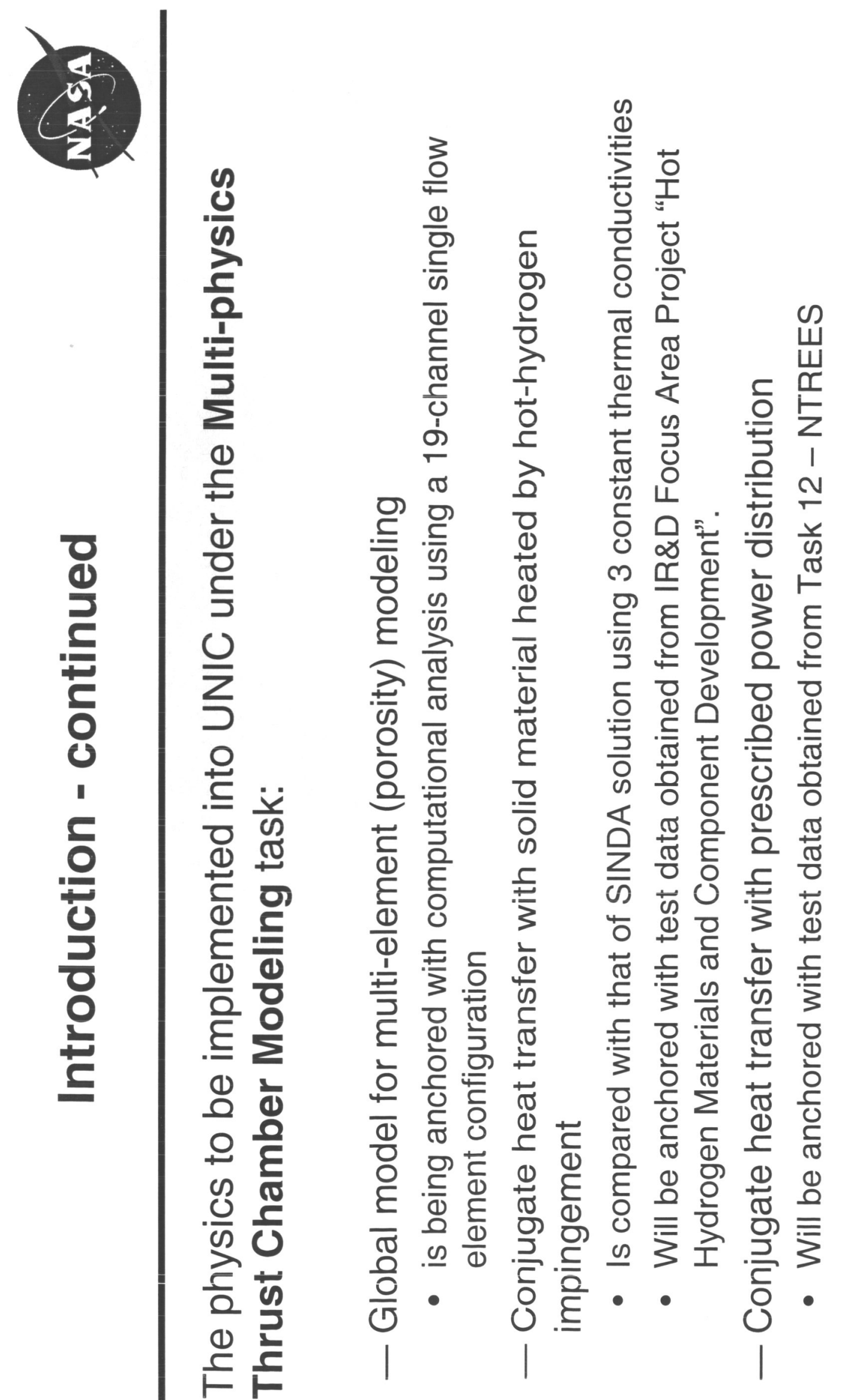




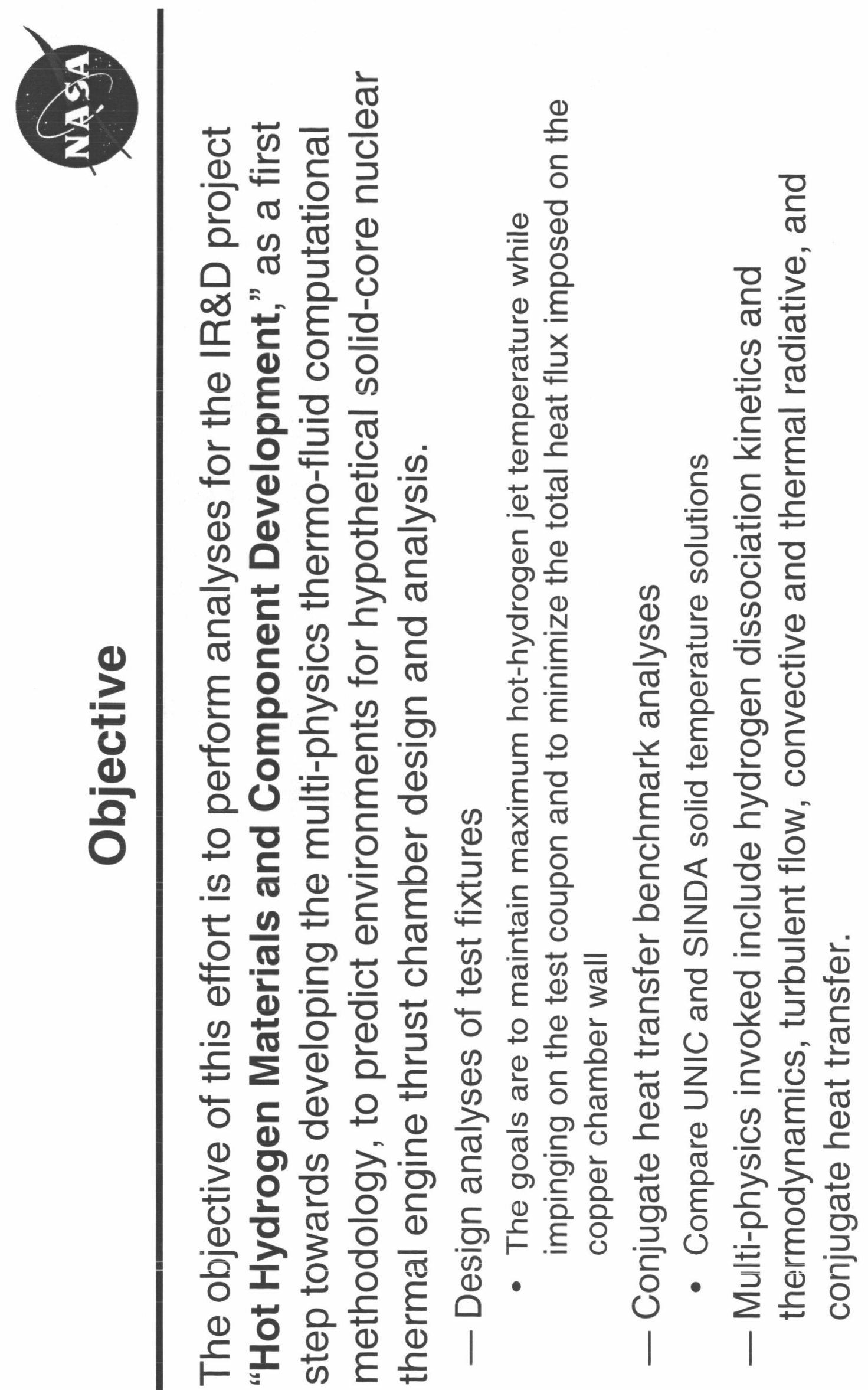




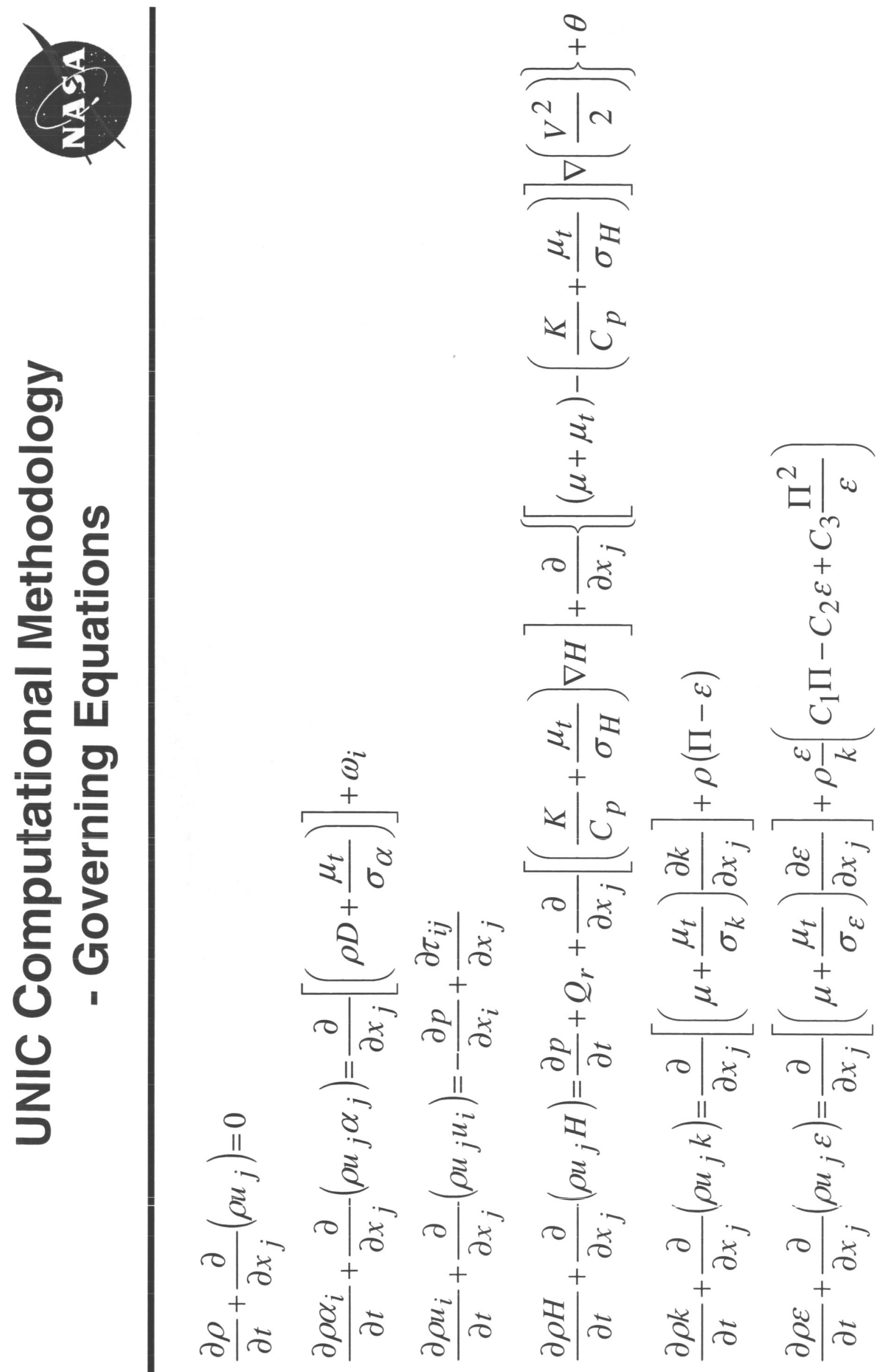




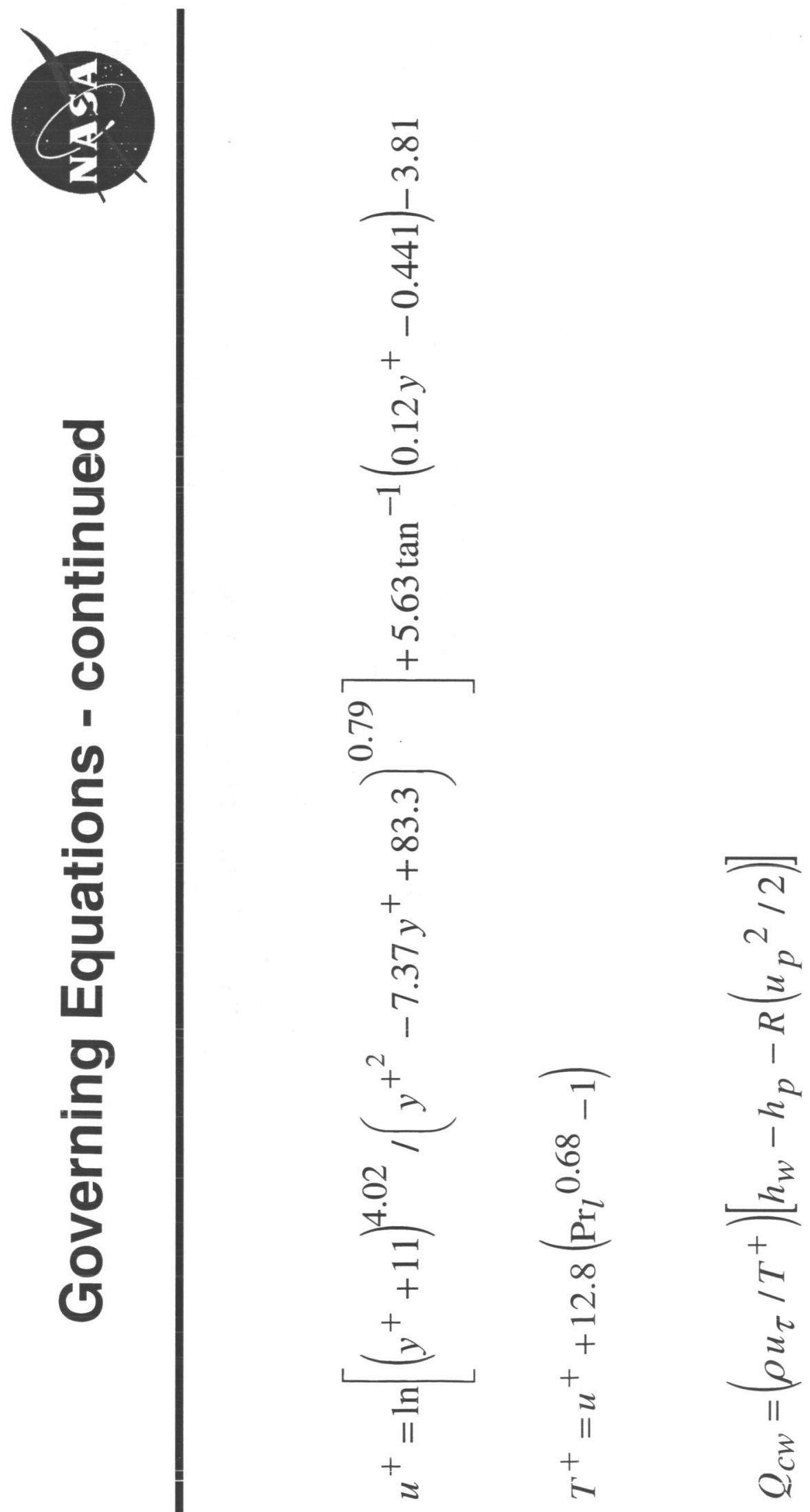



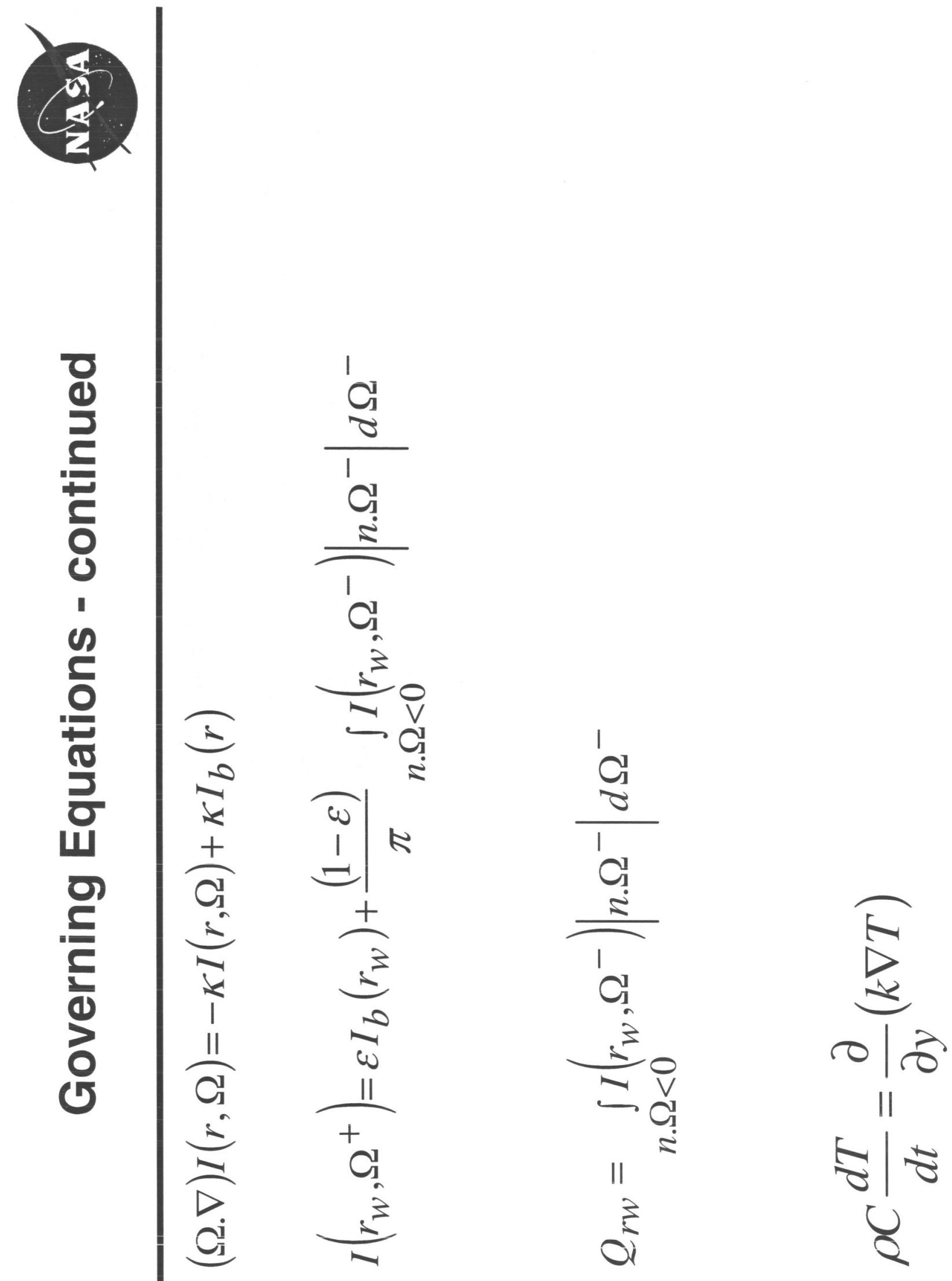


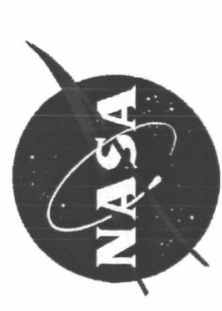

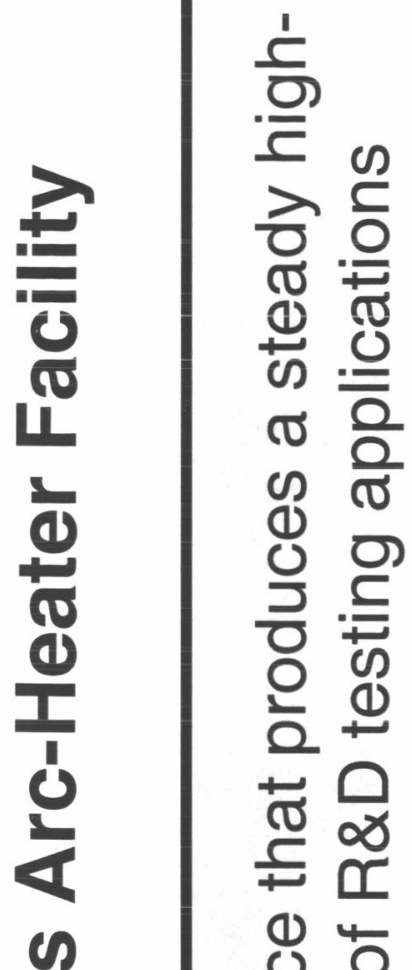

임

g

\&) $\frac{\text { D }}{0}$

崩

品

$\overline{1}$

ฮ

包

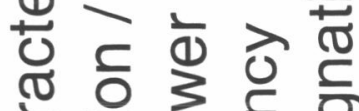

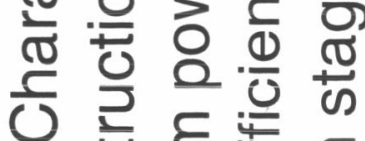

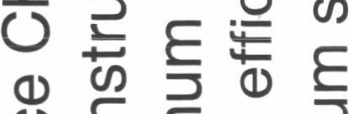

ปั

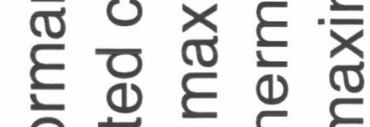

인

๑

등ำ

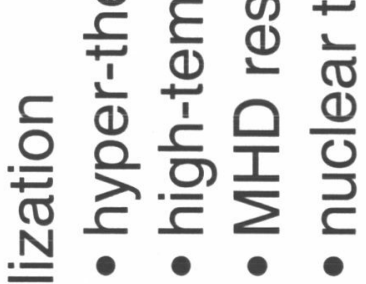

$\frac{1}{2}$

$\frac{0}{4}$

次 仓

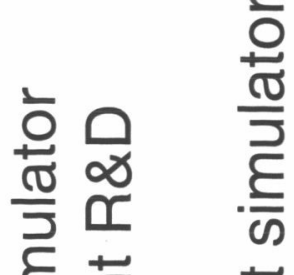

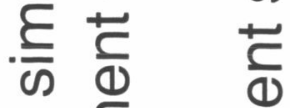

$\sum_{\geq}^{0}$

잉 일

다 0

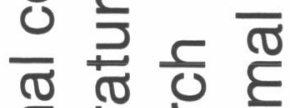

ह के क

(1) 응

$\frac{0}{\frac{0}{5}}$

ฮั

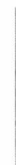

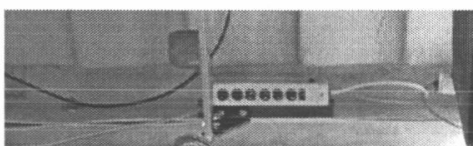

$+1$
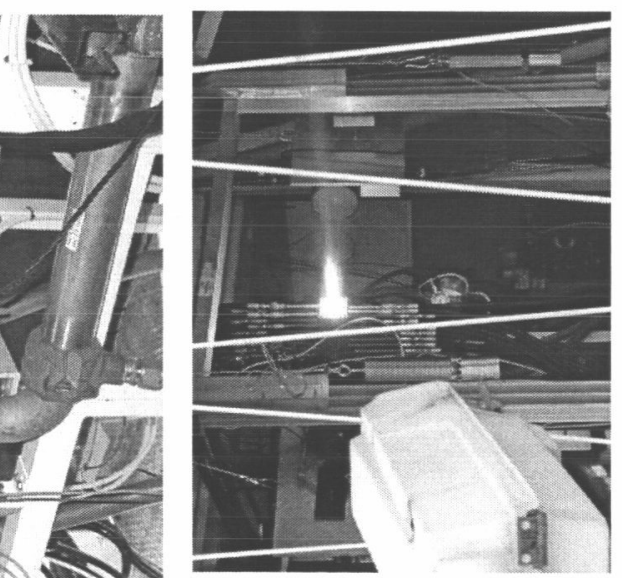

文

을 음

흐 들

<
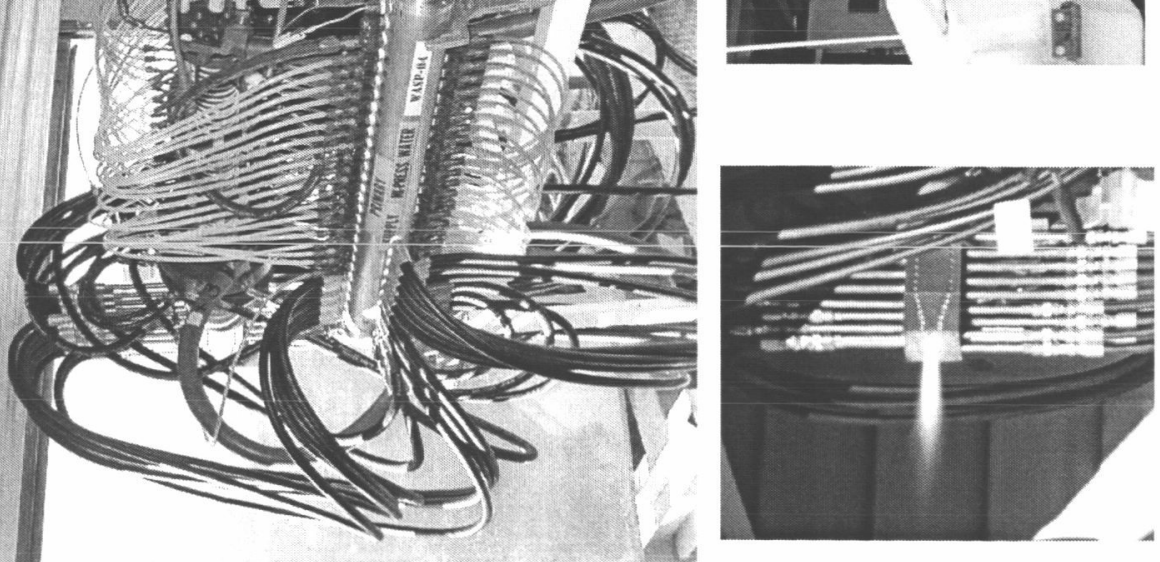

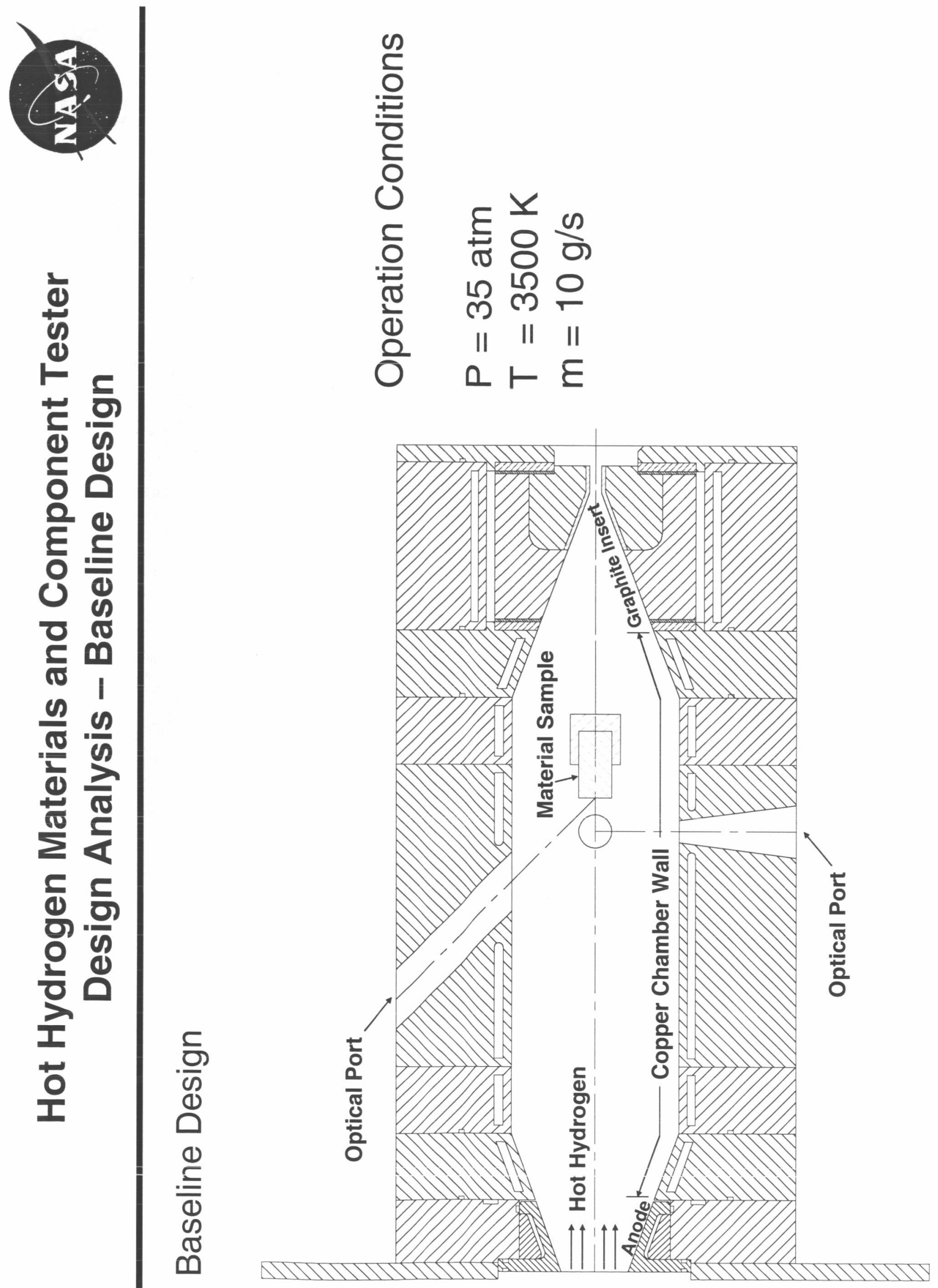


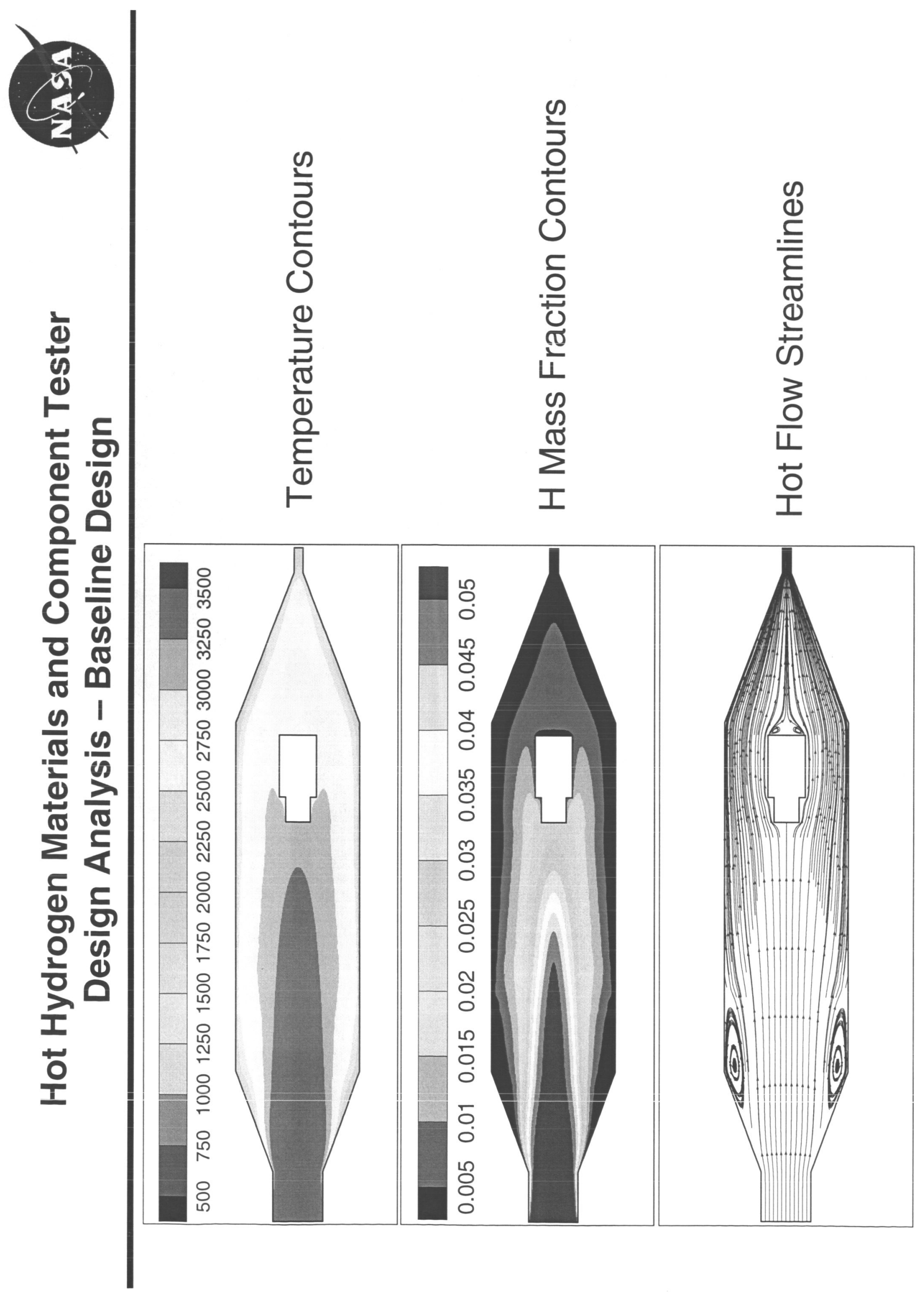



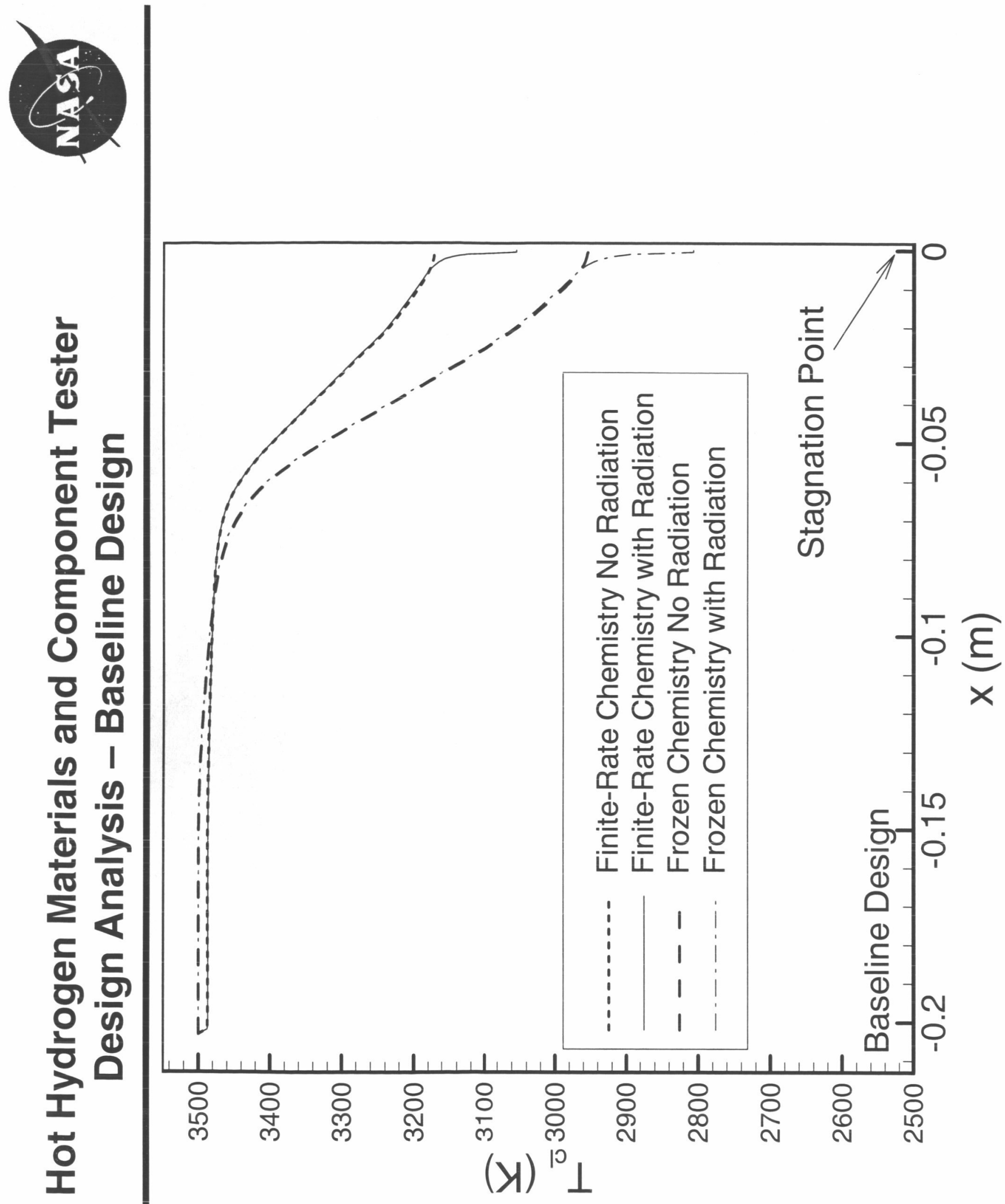

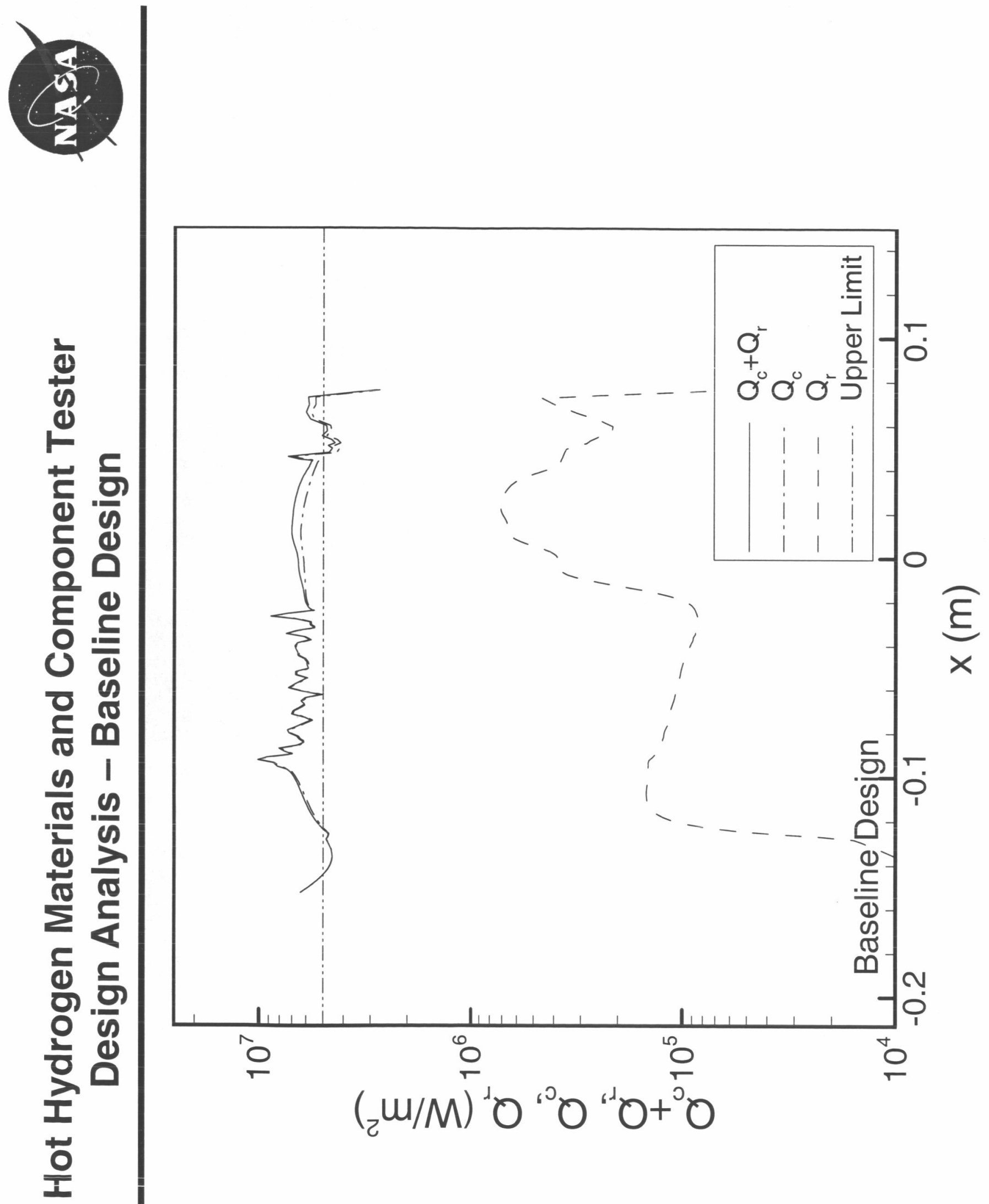

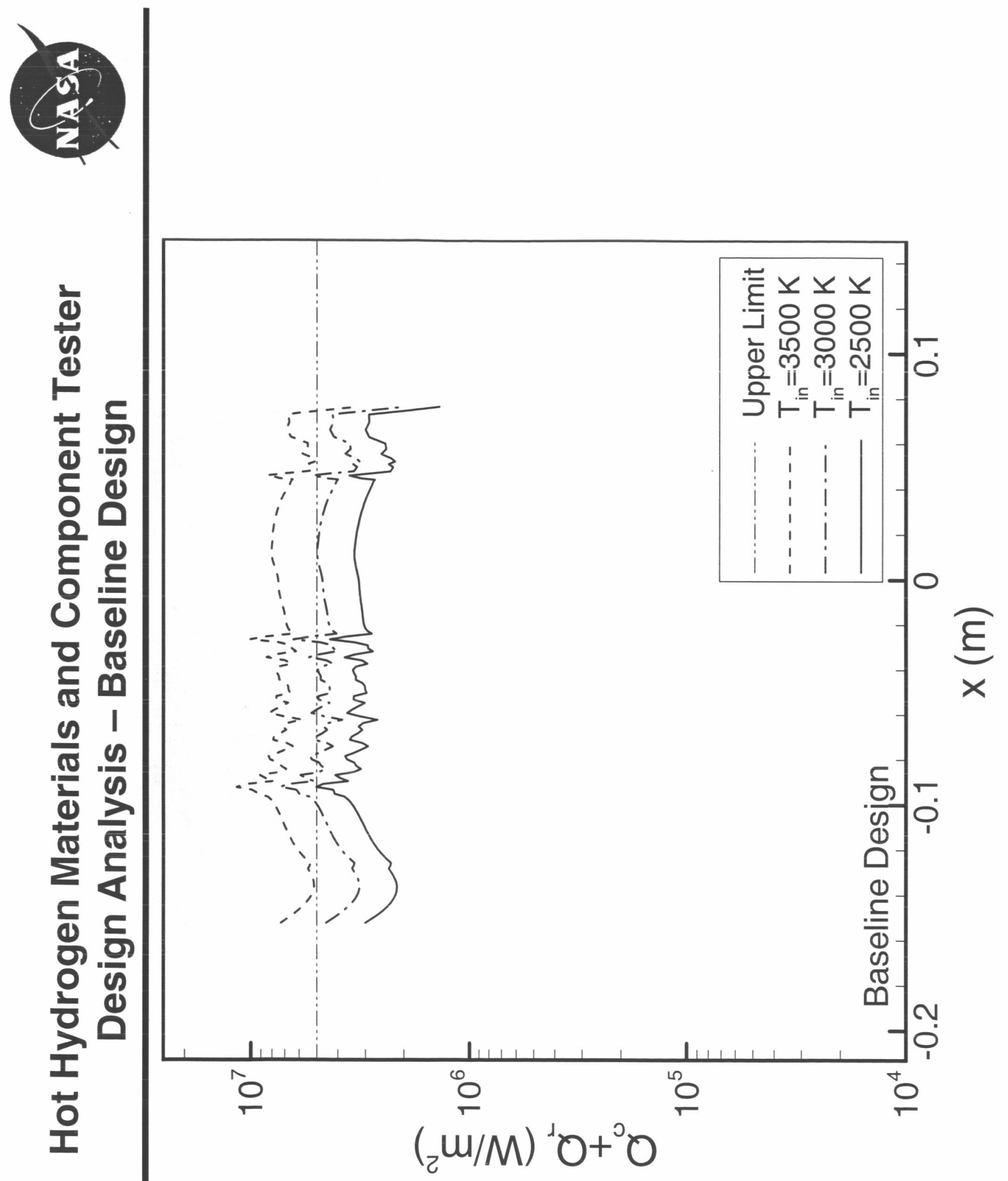

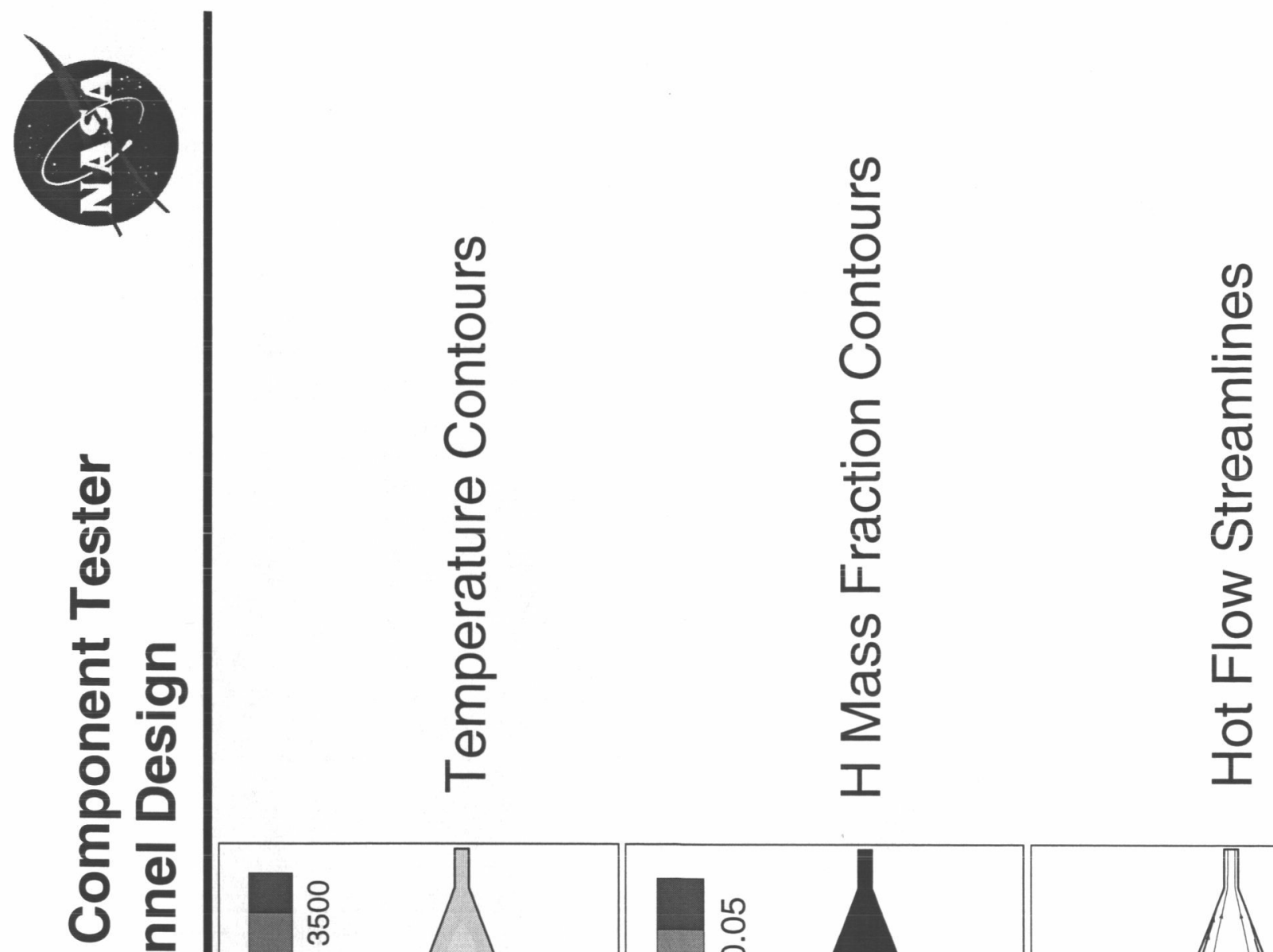

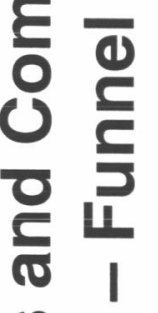

$\frac{\infty}{\infty} \frac{n}{\infty}$

竞

도 당

임

능

동
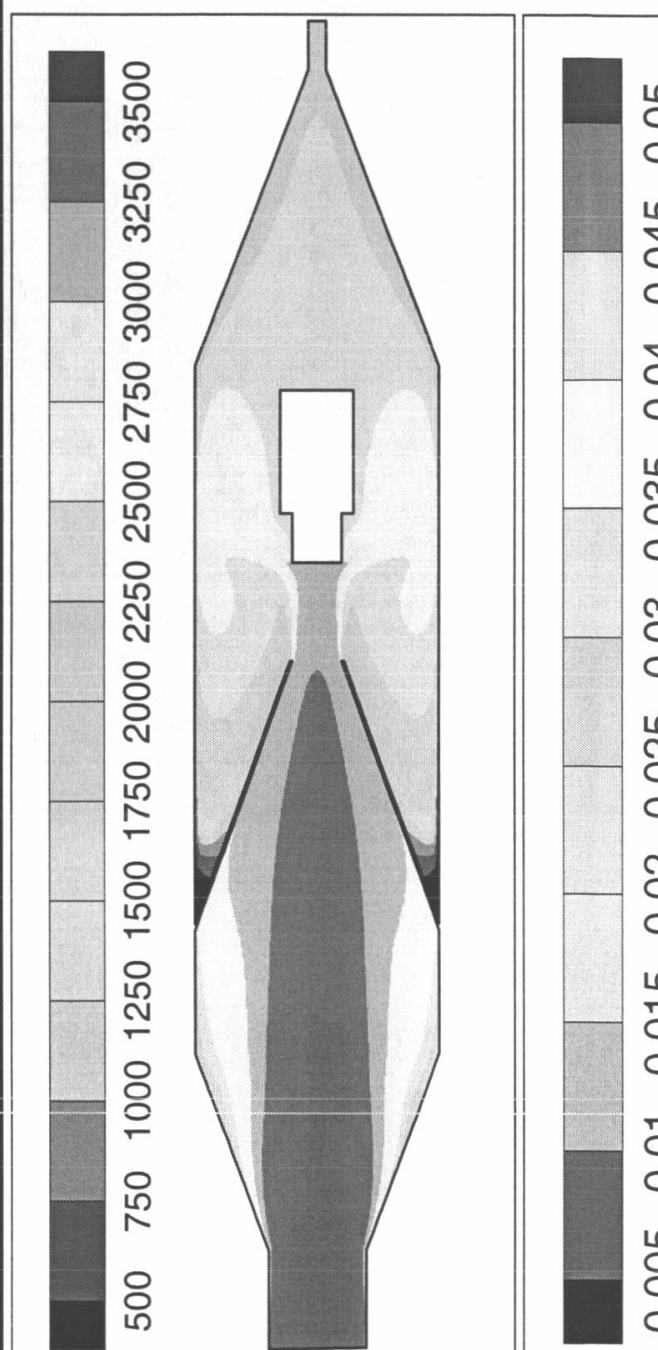

0
0
0
10
0
0

ปั

กั

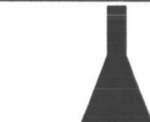

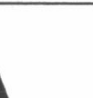

.

ọ

กิ

กิ

0

送

5

$\circ$

용 

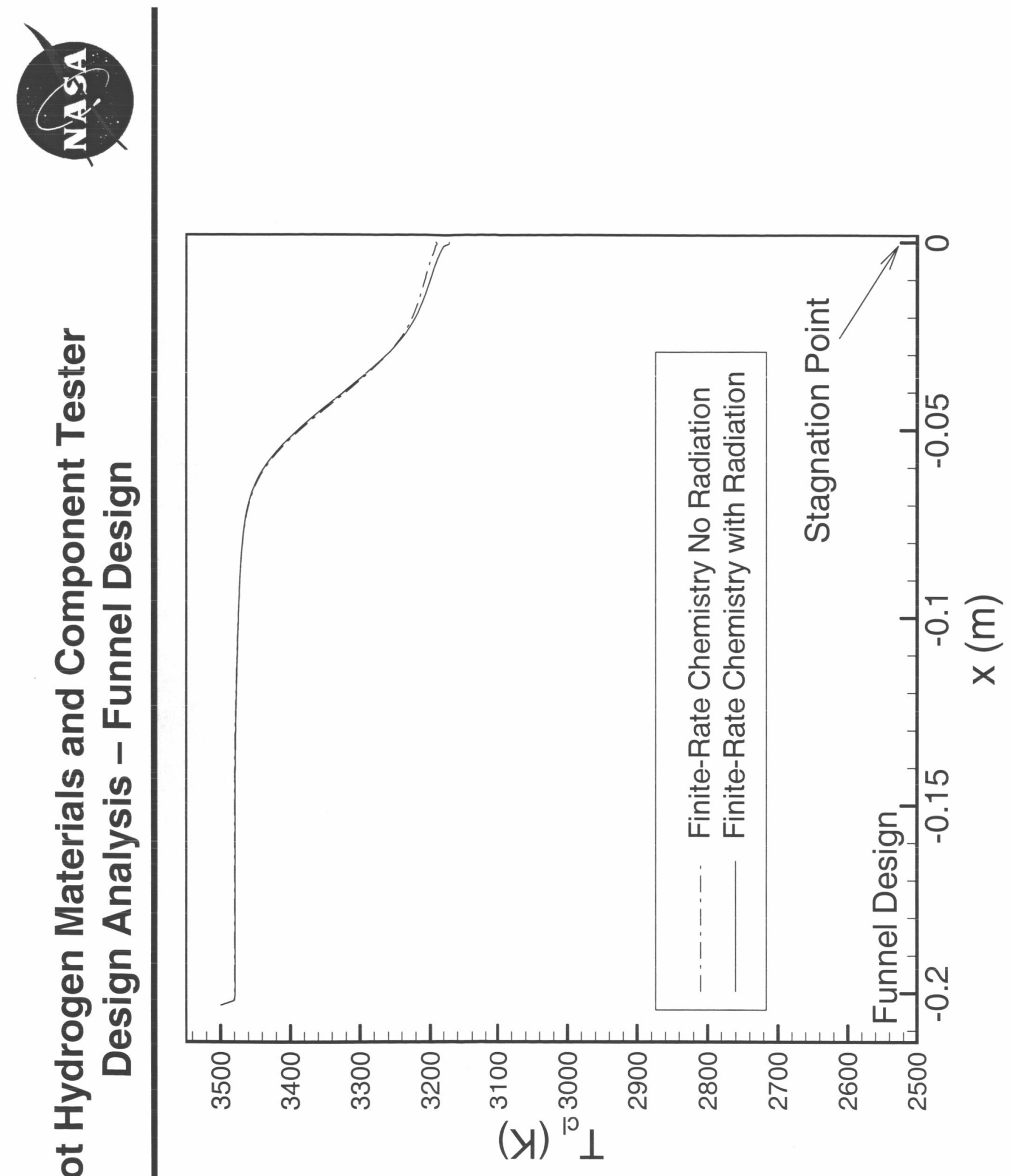

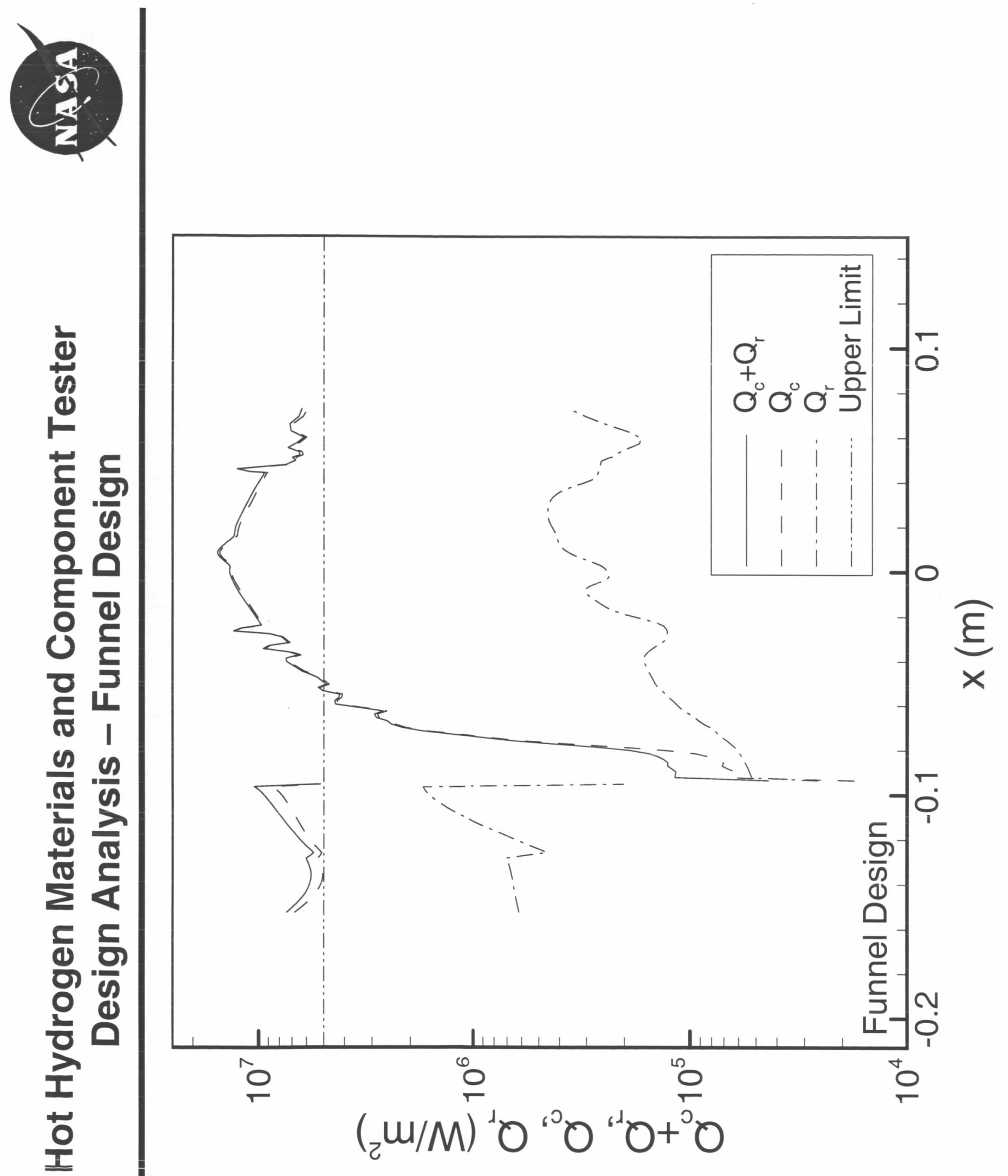

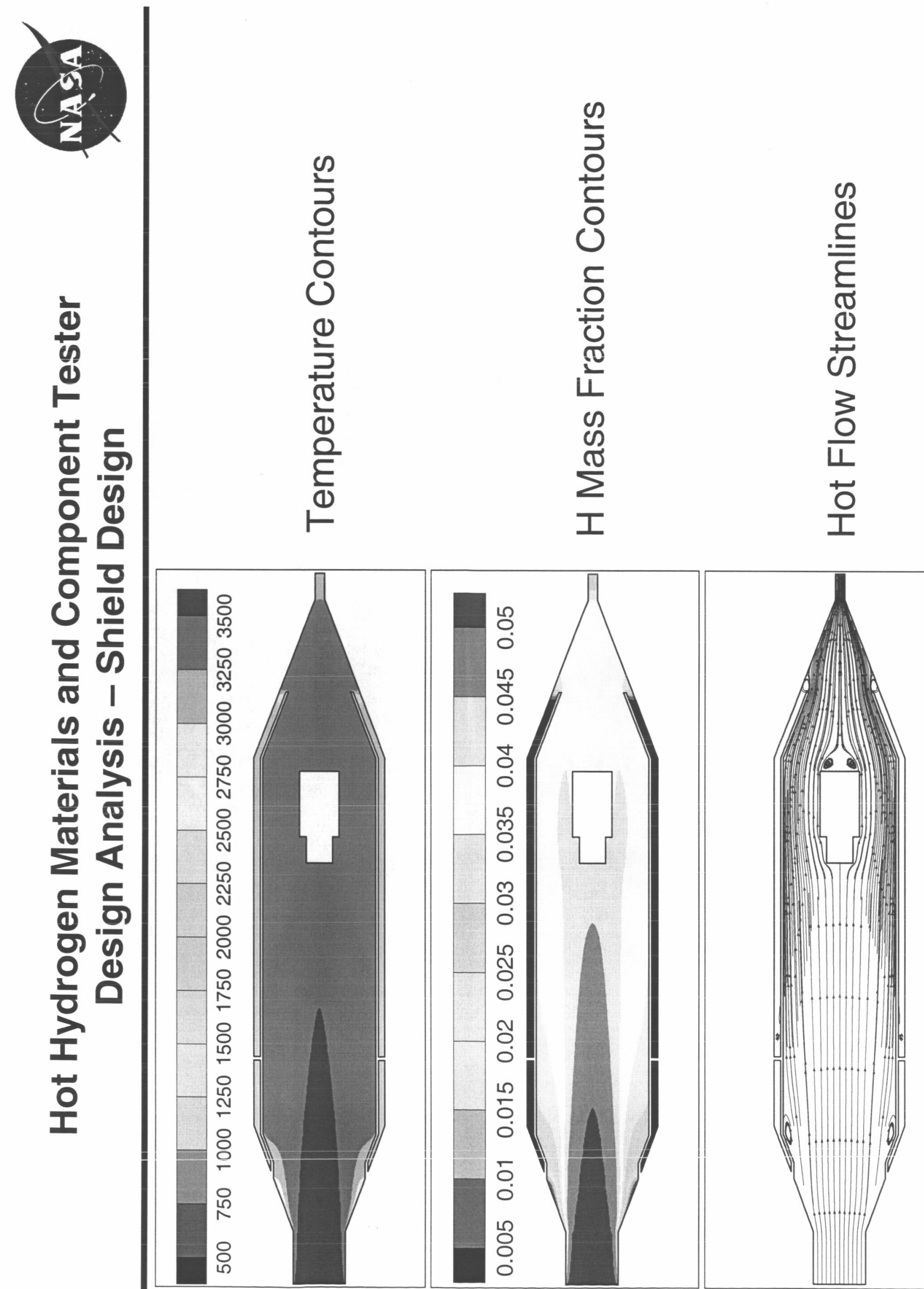


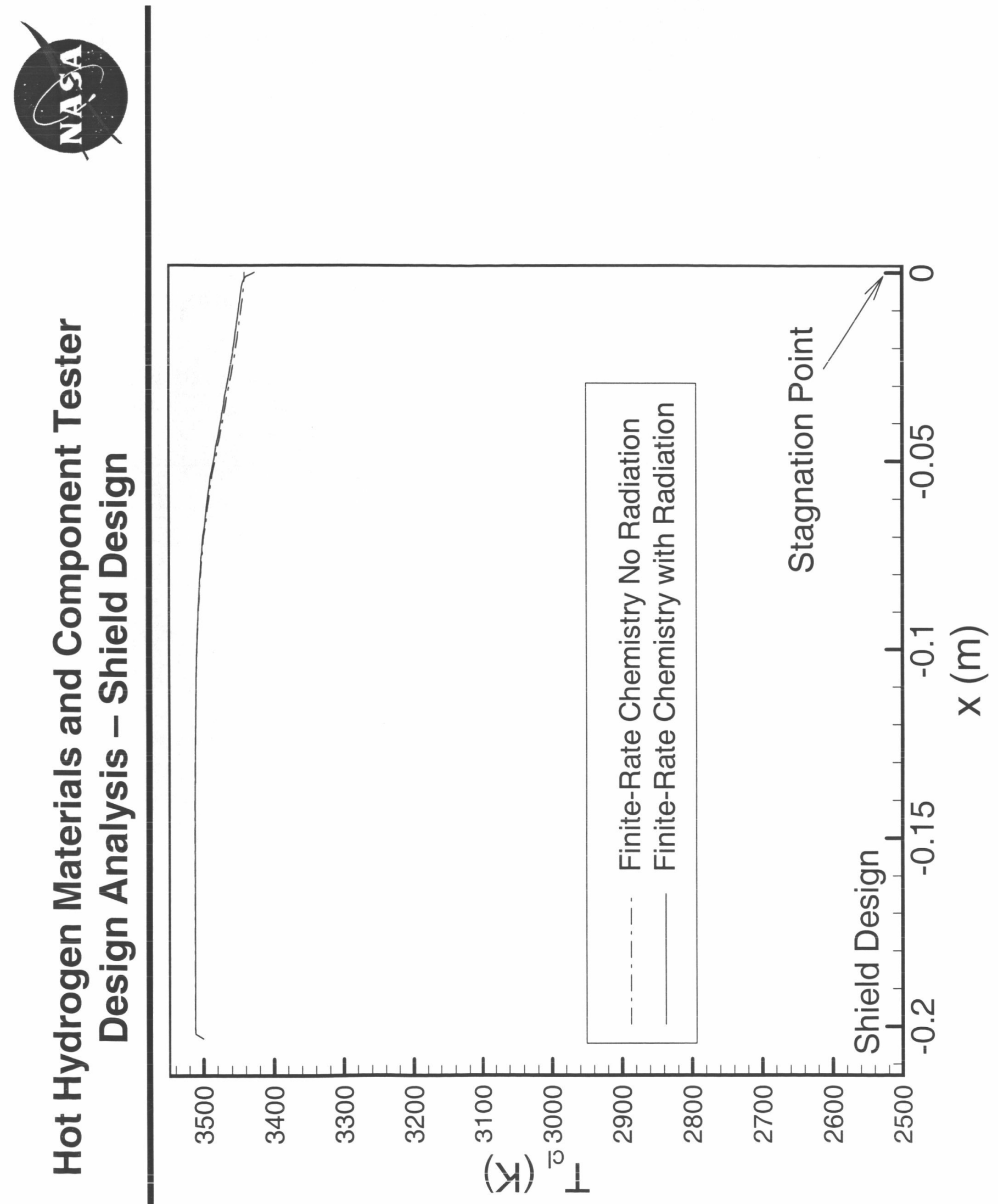



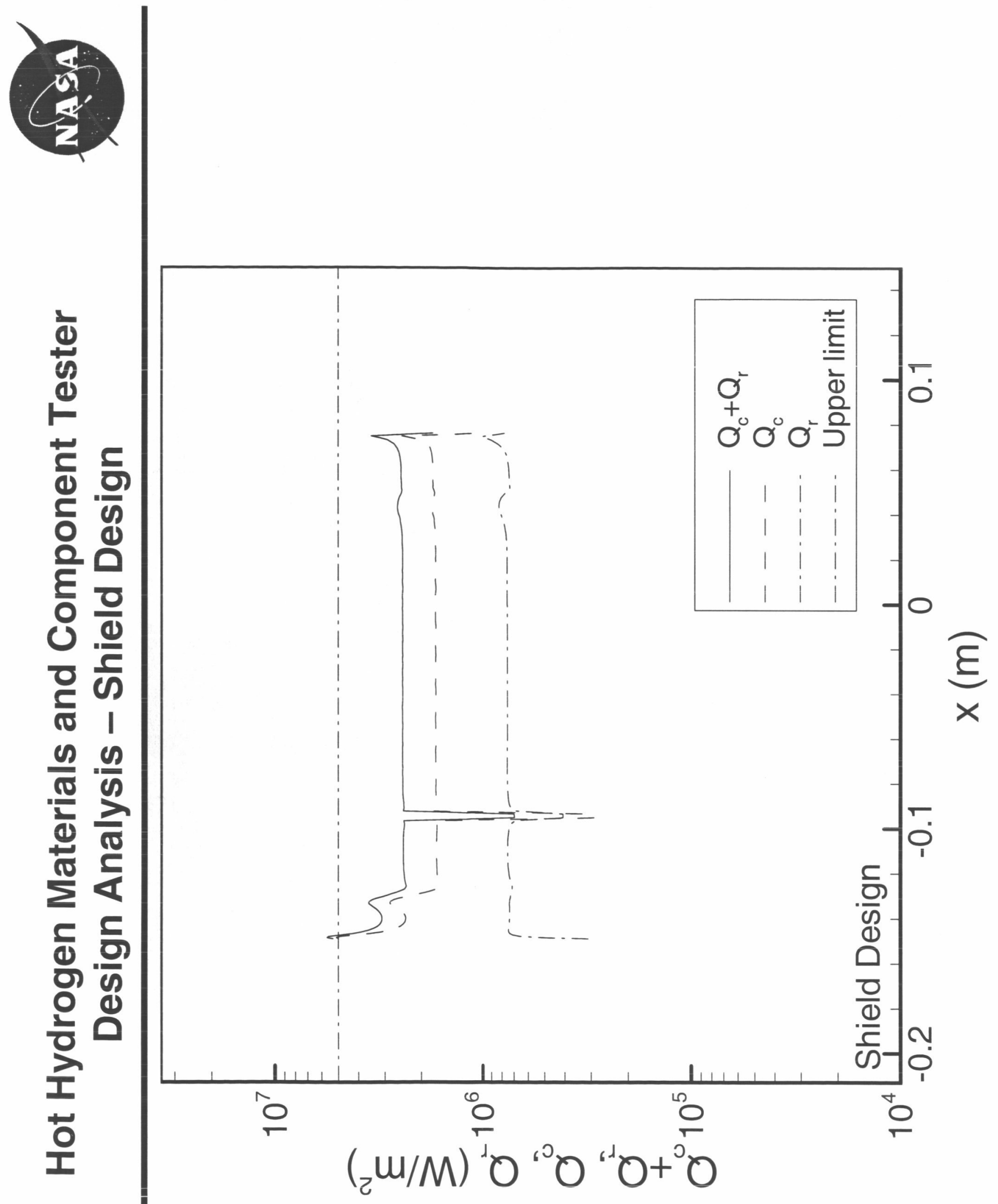


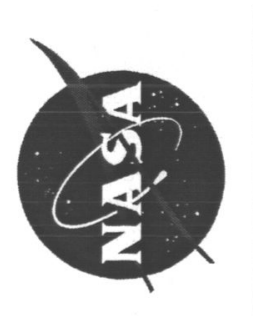

(1)

$\frac{0}{6}$

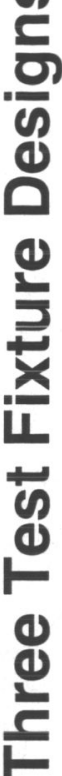

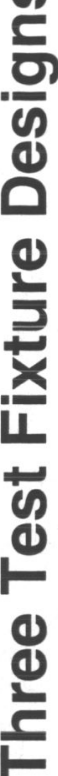

등

놀

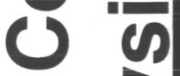

ह

(1)

(1)

120

(1) 1

(1)

룰

ชั

으

ह

(1)

8

8

드

to

2

당

के

10

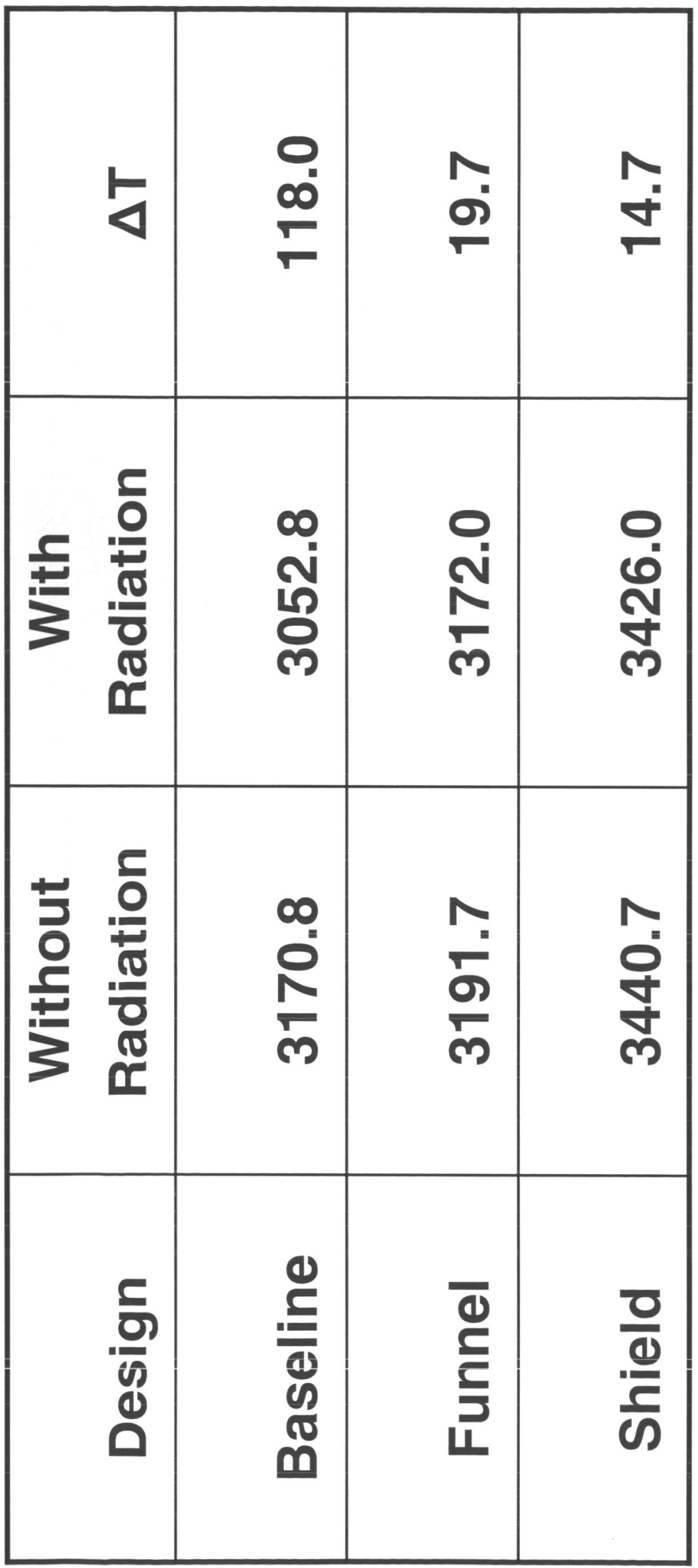

엄
$\frac{2}{3}$
릉 

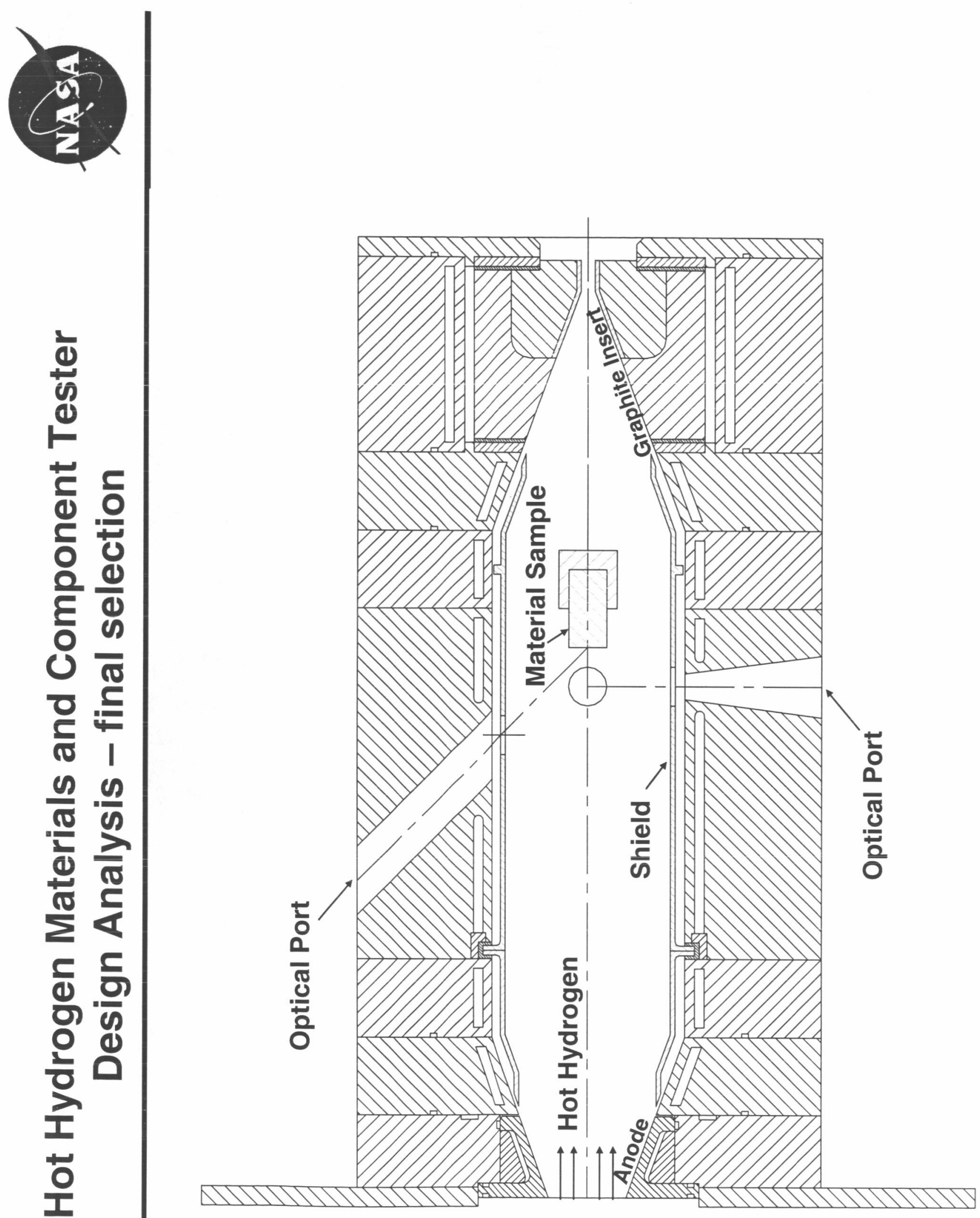


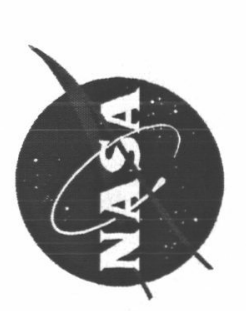

ํํำ

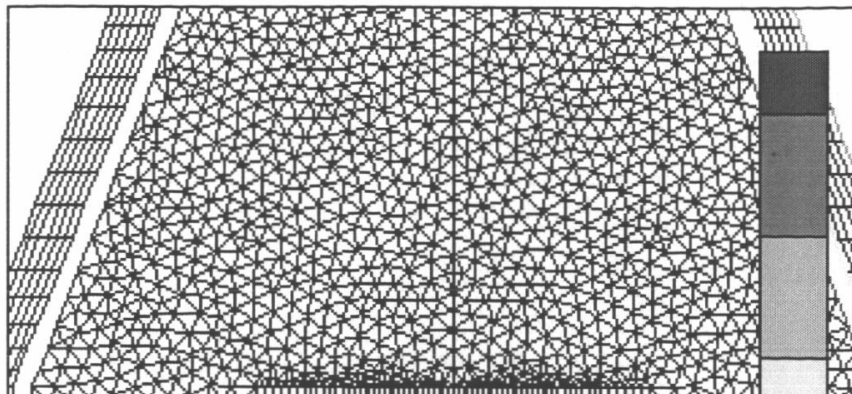

$\frac{8}{4}$

(1)

홍

竞

定

등

을
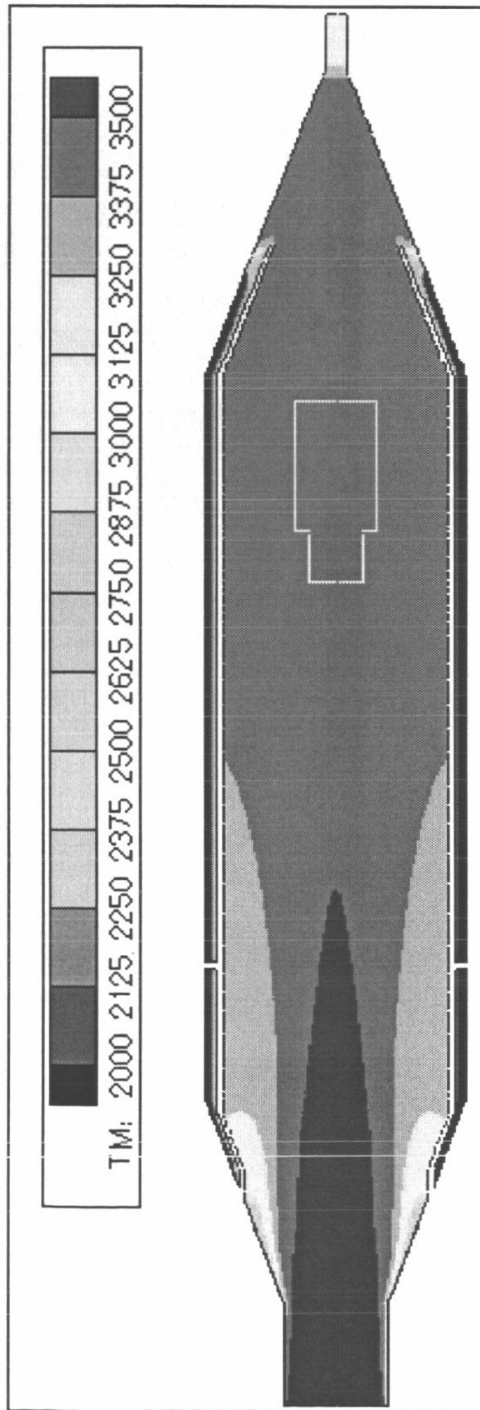

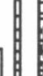
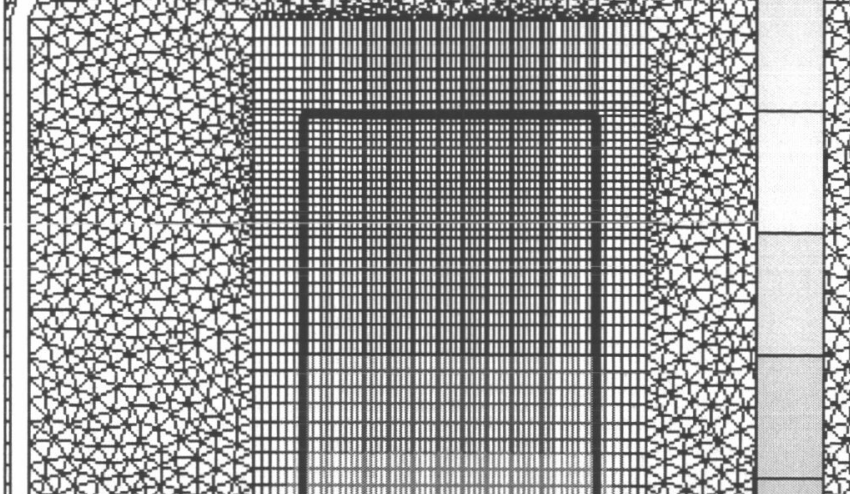

,

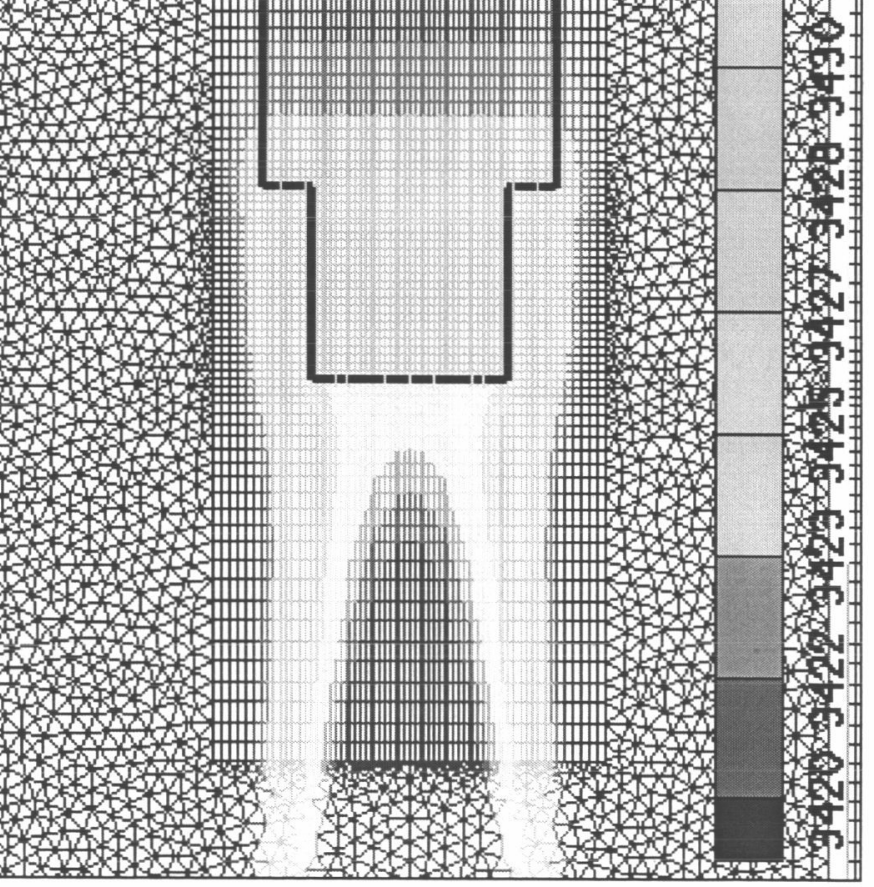

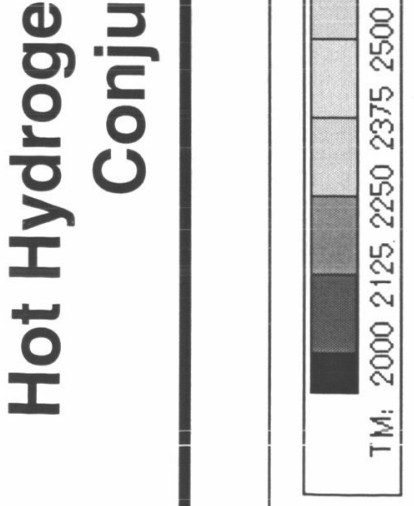




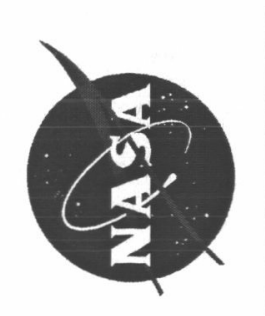

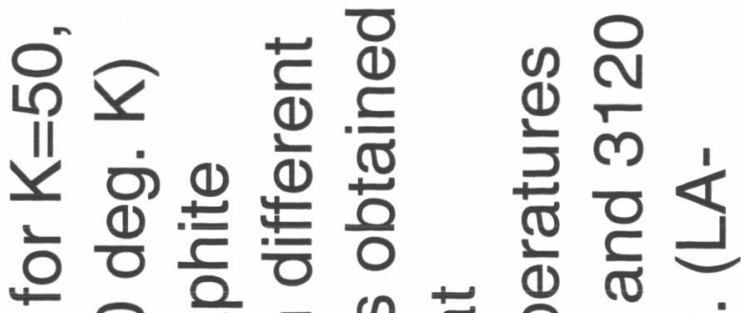

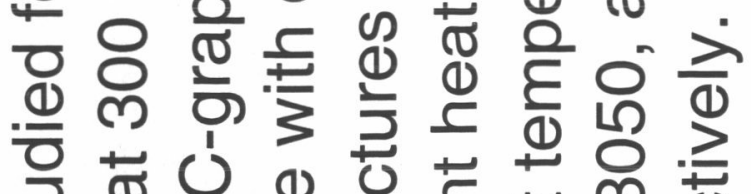

$\stackrel{\frac{1}{d}}{\frac{0}{2}}$

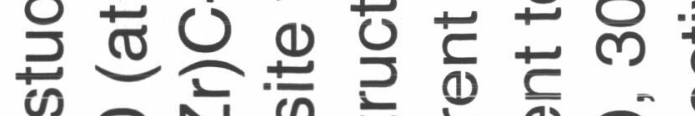

क 인

Ф글 인

ঠั

ํํำ

ह

ن

(⿻)

$\frac{n}{\pi} \cdot \frac{\infty}{\infty}$

(1) है

$\Sigma$

这

(1)

())

잉

$2+$

도

도물

$\frac{5}{5}$

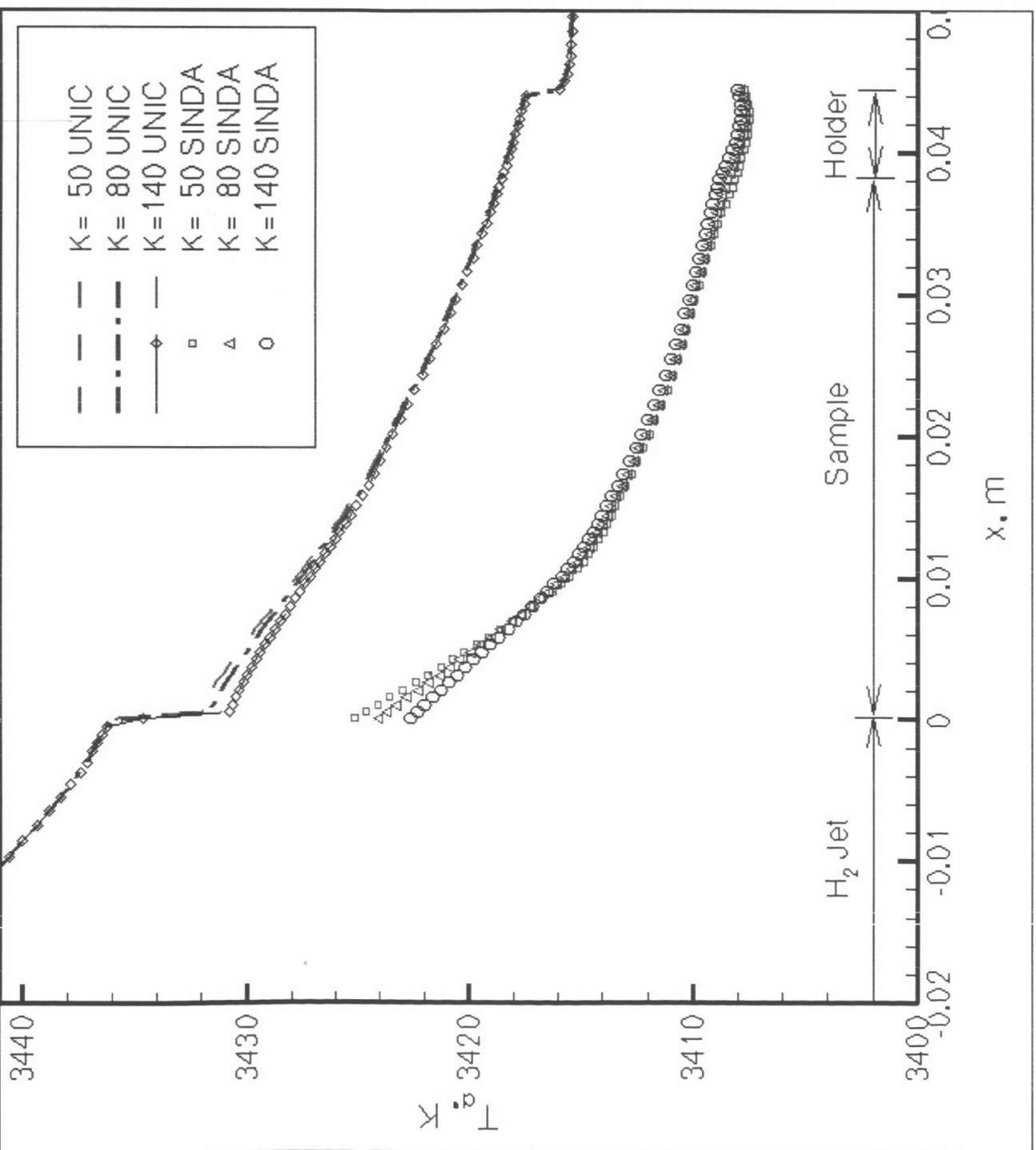




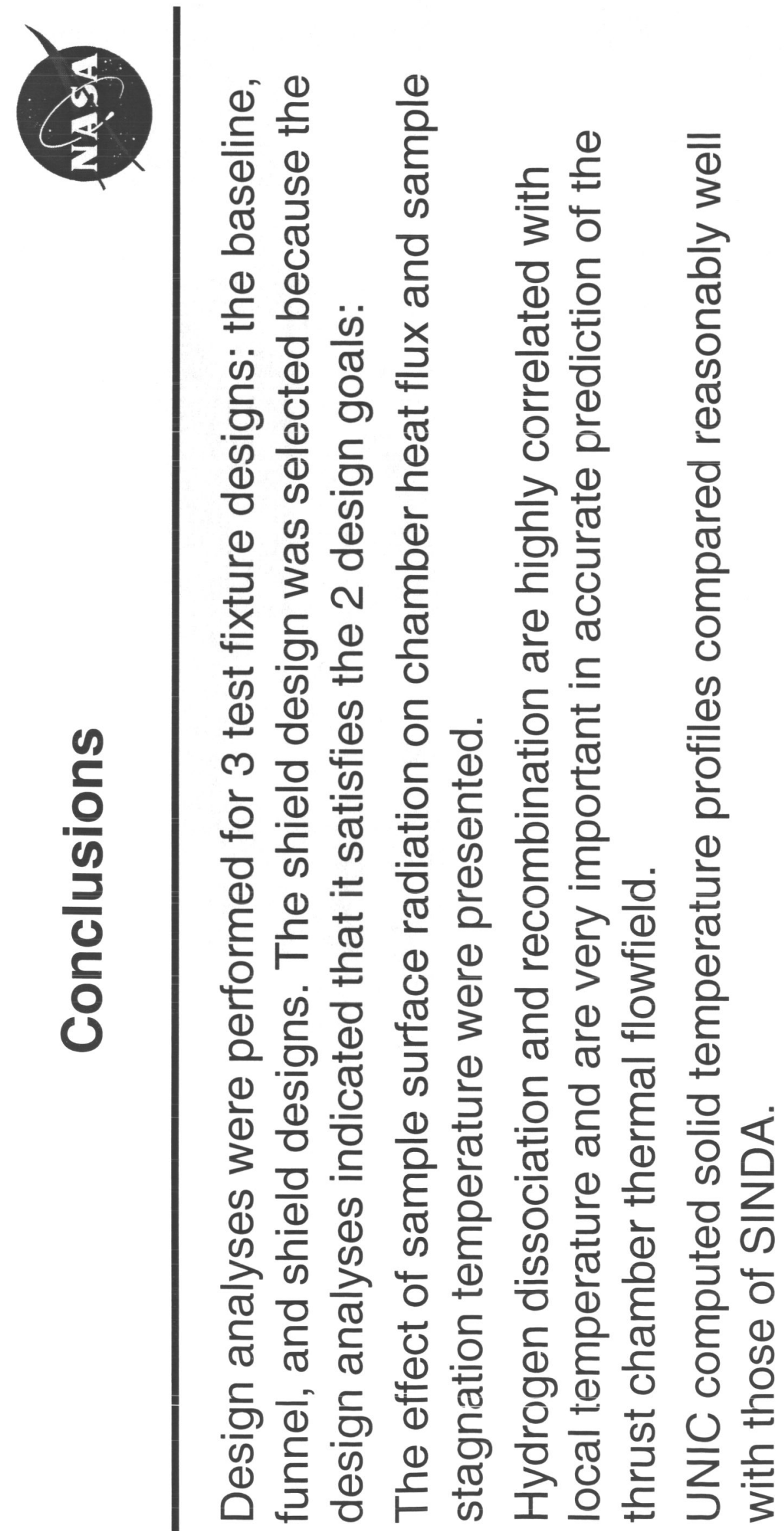

